This document is the accepted manuscript version of the following article:

Bernard, E., Lothenbach, B., Pochard, I., \& Cau-Dit-Coumes, C. (2019). Alkali binding by magnesium silicate hydrates. Journal of the American Ceramic Society, 102(10), 6322-6336. https://doi.org/10.1111/jace. 16494

\title{
Alkali binding by magnesium silicate hydrates
}

Ellina Bernard1,2), Barbara Lothenbach ${ }^{1}$, Isabelle Pochard 3 ), Céline Cau-Dit-Coumes ${ }^{4}$

1) Empa, Swiss Federal Laboratories for Materials Science and Technology, Laboratory for Concrete \& Construction Chemistry, 8600 Dübendorf, Switzerland

2) University of Bern, Institute of Geological Sciences, Rock-water interaction Group, 3012 Bern, Switzerland

3) UTINAM UMR 6213 CNRS, Université Bourgogne-Franche-Comté, 25030 Besançon, France

4) CEA, DEN, DE2D, SEAD, 30207 Bagnols-sur-Cèze cedex, France

\section{Abstract}

The binding of $\mathrm{Na}^{+}, \mathrm{K}^{+}$and $\mathrm{Li}^{+}$by magnesium silicate hydrate (M-S-H) was investigated in batch sorption experiments. Sorption isotherms and cation exchange measurements indicated the binding of alkalis in cation exchange sites compensating the negative surface charge of M-S-H. Higher $\mathrm{pH}$ values led to further deprotonation of the silanol groups and a higher alkali uptake by M-S-H. No significant incorporation of alkalis in the main silica or magnesium oxide sheets was observed. However, the silica sheets were less polymerized in the presence of higher alkali hydroxide concentrations.

\section{Keywords}

Cement, magnesium silicate hydrate (M-S-H), alkalis, sorption

\section{Introduction}

Magnesium silicate hydrate (M-S-H) phase forms as a secondary product during the degradation of cements by sea water, ground water (see e.g. (1-6)) or in a specifically case at the contact zone of cementitious materials with claystone and swelling clays (e.g. in (7-9)) or as the primary reaction product 
in magnesia silica based binders (10-16). Magnesia silica-based binders have been suggested as an option to reduce $\mathrm{CO}_{2}$ emissions caused by the production of Portland cement. The principal reaction product in such cements is M-S-H; the $\mathrm{pH}$ values of the pore solution of such cements are lower than 12 (16-18). Their use, however, is limited due to their slow hydration kinetics.

Sodium and potassium ions are present in sea water and in solutions equilibrated with clays. Relatively high concentrations of sodium or potassium are also found in the pore solution of cementitious materials as sodium and potassium usually do not precipitate as a mineral phase. However, alkali ions can be bound at the negatively charged surface of calcium silicate hydrates (C-S-H), the main solid in hydrated Portland cements. Alkali binding is higher at low calcium to silica ratios; alkalis to silica ratios up to $0.2-0.4$ have been reported $(19,20)$. The binding of alkali ions by C-S-H determines the $\mathrm{pH}$ values of the pore solution in hydrated cements and thus the stability of all other minerals. Whether and to which extent M-S-H could bind alkali is presently not well investigated, as most studies on M-S-H focus on their compositions and structures using synthetic $\mathrm{M}-\mathrm{S}-\mathrm{H}$ prepared directly from $\mathrm{MgO}$ and $\mathrm{SiO}_{2}$. Alkali ions and other cations as present both in the cement paste and in seawater and/or groundwater might change the structure, stability of M-S-H and could thus modify the durability of cements.

Experiments of Brew and Glasser (21) indicated that M-S-H could bind the alkali ions potassium and cesium. Additionally, M-S-H phases have an ill-defined structure comparable to hydrated nano-sized 2:1 and/or 1:1 phyllosilicates (22-24) and M-S-H exhibits a negative surface charge as observed by acoustophoresis and cation exchange capacity (CEC) measurements (25). As in clays, the negative surface charge is caused by the presence of deprotonated silanol groups at the edges and/or in vacancies in the silicate layers of the M-S-H. Further deprotonation of the silanol groups at higher pH values results in a more negative surface charge. CEC measurements indicates that in the absence of alkalis, the negative charge is compensated by $\mathrm{Mg}^{2+}$ present near the surface (25), or $\mathrm{Ca}^{2+}$, if calcium is present (26). 
This study investigates the ability of M-S-H to bind alkalis at different $\mathrm{pH}$ values by adding either sodium nitrate or sodium hydroxide to M-S-H during the synthesis and compared the sodium binding to lithium and potassium uptake at high pH values.

\section{Materials and methods}

\subsection{Synthesis}

Silica fume $\left(\mathrm{SiO}_{2}\right.$, Aerosil 200, containing 0.9wt.\% HCl) and magnesium oxide (Merck, pro analysis, containing $0.18 \pm 0.02$ wt. $\% \mathrm{Na}_{2} \mathrm{O}$ ) were selected as starting materials. The pure M-S-H samples were synthesized in PE-HD containers with ultra-pure water (Milli-Q water). To assure a homogeneous suspension and enough solution for analysis as ion chromatography (IC) and zeta potential measurement a water/solid (W/S) ratio of 45 was chosen. A detailed description of the synthesis is given in (27). Additionally, $\mathrm{M}-\mathrm{S}$ - $\mathrm{H}$ phases with $\mathrm{Mg} / \mathrm{Si}=0.8$ were directly equilibrated in sodium nitrate or sodium hydroxide solutions with a concentration between 10 and $500 \mathrm{mmol} / \mathrm{l}$. Sodium nitrate (AnalaR Normapure, VWR chemical) was dissolved in Milli-Q while sodium hydroxide solution (1 molar, titrisol, Merck) was diluted to reach the different concentrations wanted. Additional M-S-H 1.2 samples were synthetized in the presence of sodium nitrate, M-S-H 0.8 \& 1.0 in the presence of lithium hydroxide and potassium hydroxide. To avoid $\mathrm{CO}_{2}$ dissolution and then, its reaction, all sample handling was done in a glove box under $\mathrm{N}_{2}$.

After different curing times ( 6 months, 1 and 2 years) the suspensions were separated by filtration using pressure ( $4-5$ bars $\left.\mathrm{N}_{2}\right)$ filtration and nylon filters $(0.45 \mu \mathrm{m})$. The solids were washed with a water-ethanol mix (1:1 volume) and a second time with ethanol ( $94 \mathrm{wt} \%)$ to eliminate dissolved ions and remove the free water. The samples were dried by freezing with liquid nitrogen (at $\left.-195^{\circ} \mathrm{C}\right)$ and kept at $-40^{\circ} \mathrm{C}$ under vacuum $(0.280$ mbar pressure) for further 7 days in a freeze 
dryer. The freeze drying diminishes the carbonation as it removes quickly the free water in closed conditions. After drying the samples were gently ground by hand. The solid were characterized after further equilibration in desiccators filled with $\mathrm{N}_{2}$ over saturated with $\mathrm{CaCl}_{2}$ solution to ensure $\sim 34 \%$ RH in all the samples for a period of 14 days or longer.

\subsection{Analytical techniques}

The composition of the liquid phase was analyzed by ion chromatography (IC) immediately after filtration. The dissolved concentrations of $\mathrm{Mg}, \mathrm{Si}, \mathrm{Na}, \mathrm{NO}_{3}$ and $\mathrm{Cl}$ in undiluted solutions or in solutions diluted by factors 10, 100 and 1000 were quantified using a Dionex DP serie ICS-3000 ion chromatography system. Independent measurements of solutions with known compositions indicated a measurement error $\leq 10 \%$. The $\mathrm{pH}( \pm 0.1)$ was measured at ambient temperature $\left(23 \pm 2^{\circ} \mathrm{C}\right)$ in the supernatant in an aliquot of the unfiltered suspension where the solid particles had been allowed to settle. The measured $\mathrm{pH}$ values obtained were corrected to 20 or $50{ }^{\circ} \mathrm{C}$. No relevant changes in the aqueous phase composition are expected during the short cooling down the solutions to ambient temperature from $50{ }^{\circ} \mathrm{C}$, as $\mathrm{M}-\mathrm{S}$-H precipitation occurs only very slowly and as no significant differences in the measured concentrations between diluted and not-diluted solutions were observed. Additionally, in high alkali hydroxide concentration systems, in order to minimize the alkali error, fresh alkali hydroxide solutions with known conductivity were measured (10 mmol/l to 500 $\mathrm{mmol} / \mathrm{l})$.

Thermogravimetric (TG) data were collected using a Mettler Toledo TGA/SDTA 8513 instrument with a heating rate of $20^{\circ} \mathrm{C}$ per min from 30 to $980^{\circ} \mathrm{C}$ on ground powder; approximately $30 \mathrm{mg}$.

X-ray diffraction (XRD) was carried out on a PANalytical X'Pert Pro MPD diffractometer apparelled with a rotating sample stage in a $\theta-2 \theta$ configuration applying $C u K \alpha$ radiation $(\lambda=1.54 \AA)$ at $40 \mathrm{~mA}$ intensity and $45 \mathrm{mV}$ voltage and a X'Celerator detector. The samples were scanned between $5^{\circ}$ and $75^{\circ} 2 \theta$. 
X-ray Pair Distribution Function (PDF) analyses were carried out on X'Celerator Panalytical diffractometer equipped with a Mo source $\left(\lambda_{\mathrm{k}_{\alpha}}=0.70926 \AA\right)$. The powder diffraction pattern was scanned over the $6.004-153.932^{\circ}$ angular range with a step size of $0.0083^{\circ}$. The total acquisition was the average of 2 runs recorded over 24 hours.

This analysis focusses on the entire signals including Bragg peaks and diffuse scattering. The experimental PDF expresses the distribution of interatomic distances in a compound, independently of its crystalline state, calculated by a Fourier transform of the measured powder pattern. PDF is therfore an efficient analysis for studying of nanocrystalline phase, disordered and amorphous materials as cement hydrates as C-S-H (28). The reduced PDF, G(r), was obtained by taking a sine Fourier transform of the measured total scattering function $S(Q)$, as shown in equation (1), where $Q$ is the momentum transfer given in equation (2) with $\theta$ as the scattering angle and $\lambda$ as the wavelength of the incident radiation $(29,30)$.

$G(r)=\frac{2}{\pi} \int_{Q_{\min }}^{Q_{\max }} Q[S(Q)-1] \sin \left(Q_{r}\right) d Q$

$Q=\frac{4 \pi \sin \theta}{\lambda}$

The PDF and standard corrections (30) were calculated with PDFGetX2 (31). The density number of atoms $\rho_{0}$ used to calculate the PDF was 0.10 atoms $\AA^{-3}$. The use of a finite value of $Q(17 \AA)$ for the PDF analysis led to the addition of spurious oscillations to G(r) depending on the distance r. These oscillations were smoothed by the use of a Lorch (1969) function. On the other hand, calculated PDF from a given structure was obtained with PDFGui (32). Due to limited Q resolution, a value of 0.05 Gaussian dampening $\left(Q_{\text {damp }}\right)$ envelope was introduced in the refinement.

The ${ }^{29} \mathrm{Si}$ MAS NMR data were recorded on a Bruker Avance III NMR spectrometer using a $7 \mathrm{~mm}$ CP/MAS probe at $79.5 \mathrm{MHz}$ with the following parameters for the single pulse experiments: $4500 \mathrm{~Hz}$ sample 
rotation rate, minimum of 3072 scans, $30^{\circ}{ }^{29} \mathrm{Si}$ pulse of $2.5 \mu \mathrm{s}, 20 \mathrm{~s}$ relaxation delays, RF field strength of $33.3 \mathrm{kHz}$ during SPINAL64 proton decoupling. The ${ }^{29} \mathrm{Si}$ NMR chemical shifts of the spectra were referenced to the intense resonance at $-2.3 \mathrm{ppm}$ of an external sample of an octamethylsilsesquioxane (Aldrich No. 52,683-5) which was referenced to tetramethylsilane (TMS, $\delta^{29} \mathrm{Si}=0.0 \mathrm{ppm}$ ). The ${ }^{29} \mathrm{Si}$ resonances were analyzed and described using the $\mathrm{Q}^{\mathrm{n}}$ classification depending on a silicate site connectivity. The quantification was carried out by nonlinear least-square fits with the software "DMFIT" (33). The details of the deconvolutions of the M-S-H spectra can be found in (27).

The suspensions $(\mathrm{W} / \mathrm{S}=45)$ were directly used before filtration to measure the zeta potential. To avoid some agglomerates after months of equilibration and to have the M-S-H particles in a homogeneous suspension, magnetic stirrer was used at $500 \mathrm{rpm}$ during 10 minutes. The measurements are re-do 10 times over $12 \mathrm{~min}$ at a stirring rate of $400 \mathrm{rpm}$, the error of the measurement is $\pm 10 \%$. Zeta potential data were recorded on a ZetaProbe from Colloidal Dynamics Inc., which is based on the frequencydependent electroacoustic effect and the zeta potential is calculated from the frequency-dependent mobility using the O'Brien equation (34). A background correction with a measurement of the filtrated aqueous phase was applied. The zeta potential is measured close to the interface between the stern layer and the diffusive layer giving the effective charge of the particle in suspension $(35,36)$. To avoid the large change of the diffusive layer length, only the samples synthesized at low alkali concentrations $(\leq 100$ mmol/l) were of interest.

Cation exchange capacity (CEC) of the M-S-H samples was measured on dried powder. A solution of cobalt hexamine trichloride (4g/l, Sigma-Aldrich, assay: 99\%) was chosen for the high capacity of $\mathrm{Co}^{3+}$ to replace the cations on the surface and/or from the interlayer. The suspensions were filtered and the concentrations of $\mathrm{Na}, \mathrm{K}, \mathrm{Li}, \mathrm{Ca}, \mathrm{Mg}$ in solution were measured by ion chromatography (IC). The sum of measured cations was compared to the total CEC, which was obtained from the difference in the cobalt hexamine concentration from the original solution and from the leachate. Such concentrations were determined by colorimetry (absorption band at $473 \mathrm{~nm}$ ) using a UNI-CAM UV visible spectrometer. To 
test whether any dissolution of the M-S-H occurred during CEC measurements, a part of the samples were also put in milliQ water $/ \mathrm{HCl}$ solution with the same $\mathrm{pH}$ as the cobalt hexamine trichloride solution. The ions concentration of this washing showed negligible dissolution and low free alkali concentrations indicating that the cations measured in the solution after CEC correspond effectively to the exchangeable cations.

\section{Results and discussions}

\subsection{M-S-H as the main reaction product}

\subsubsection{Effect of sodium nitrate on M-S-H}

Most synthesis of M-S-H reported in literature have been carried out using $\mathrm{MgO}$ and $\mathrm{SiO}_{2}$ in water, where M-S-H forms very slowly and $\mathrm{pH}$ values between 8 and 10.5 were observed. At room temperature it can take up to 2 years until equilibrium has been reached (27). M-S-H synthesized in water exhibited broad X-rays signals characteristic of M-S-H at 19.7, 26.7, 35.0, and $59.9{ }^{\circ} 2 \theta$ $(\lambda=1.54 \AA ీ)(23-25)$ as also shown for pure M-S-H 0.8 in Figure 1. X-ray diffraction patterns of the MS-H 0.8 synthesized in the presence of sodium nitrate presented similar patterns with broad X-rays humps as detailed above. Residual sodium nitrate was only found in the samples where the solution used during synthesis contained $\left[\mathrm{NaNO}_{3}\right]=500 \mathrm{mmol} / \mathrm{l}$, maybe due to its precipitation during the drying. In the presence of sodium nitrate, the reflection at approx. $60^{\circ} 2 \theta$ characteristic for the main layer in trioctahedral smectites such as stevensite or saponite appears narrower, while the broad signal at $26.7^{\circ} 2 \theta(003)$, which had been related to the basal specing of M-S-H (25), seems more intense. TGA analysis (Figure 2) showed the presence of physically bound water (weight loss 30$\left.250^{\circ} \mathrm{C}\right)$ and structurally bound water, i.e., the hydroxyl groups $\left(250-800^{\circ} \mathrm{C}\right)$ typical to $\mathrm{M}-\mathrm{S}-\mathrm{H}(10,23)$. The physically bound water content is strongly dependent on the relative humidity and the drying methods (25), and it seems that its content increases with the addition of sodium nitrate. 
The ${ }^{29} \mathrm{Si}$ MAS-NMR spectra of M-S-H in the presence of $\mathrm{NaNO}_{3}$ are compared to pure M-S-H 0.8 in Figure 3. The ${ }^{29} \mathrm{Si}$ MAS NMR spectrum of pure M-S-H shows resonances at around -78.6 ppm assigned to $\mathrm{Q}^{1}$, -85.5 ppm $\left(\mathrm{Q}^{2}\right)$ and mainly $\mathrm{Q}^{3}$ (large hump between -92.5 and -96.7 ppm) tetrahedral silicates (23-25). The high $\mathrm{Q}^{3}$ content in M-S-H indicates a structural similarity to low crystallinity and nano-crystallite phyllosilicates; however, the exact position of these different $\mathrm{Q}^{3}$ sites is not yet resolved. In the presence of sodium nitrate, the samples contained a comparable amount of amorphous silica ( $\sim 4 \%$ of the initial silica fume) as without sodium nitrate. Also, the content of $\mathrm{Q}^{1}$ and $\mathrm{Q}^{2}$ tetrahedral silicate $\left(1-2 \% \mathrm{Q}^{1}\right.$ and $\sim 30 \% \mathrm{Q}^{2}$ of the total silicon present) was comparable to the pure M-S-H sample as well as the total amount of $\mathrm{Q}^{3}$ tetrahedral silicate. However, the addition of sodium nitrate slightly increased the amounts of $\mathrm{Q}^{3} \mathrm{a}$ and $\mathrm{Q}^{3} \mathrm{~b}$ and decreased the amount of $\mathrm{Q}^{3} \mathrm{c}$ as shown in Figure 3. It can be expected that sodium instead of magnesium at the cation exchange surface sites of M-S-H in the vicinity of silicate (25) could decrease shielding and thus lead to less negative chemical shifts (37). However, the $\mathrm{Q}^{2}$ position peak should be even more affected but no or only a very small shift in the $\mathrm{Q}^{2}$ position is observed in the presence of sodium nitrate. Thus, it seems the higher $\mathrm{Q}^{3} \mathrm{a}(-93 \mathrm{ppm})$ content indicates some changes in the $\mathrm{T}: 0$ structure and not be related to sodium in the cation exchange sites. In fact the presence of more $\mathrm{Q}^{3} \mathrm{a}$ in the presence of high $\mathrm{NaNO}_{3}$ concentrations could indicate a rearrangement of magnesium resulting in structure containing less T:O:T layers (such as talc with a band at $-97 \mathrm{ppm}(38)$ ) but more T:0 layers like serpentine group minerals (signal at -93 ppm (39)).

Comparable changes were observed for M-S-H 1.2 samples synthesized in the presence of sodium nitrate (data not shown): M-S-H-like phases as main reaction product with comparable water content of water, mainly $\mathrm{Q}^{3}$ silica species and the presence of more $\mathrm{Q}^{3} \mathrm{a}$,b in the presence of $\mathrm{NaNO}_{3}$ 
A summary of the solution compositions of the samples synthesized at $20^{\circ} \mathrm{C}$ is given in Table 1. The pure M-S-H sample (Mg/Si=0.8) contained $1.4 \mathrm{mmol} / \mathrm{l}$ of silicon and $0.4 \mathrm{mmol} / \mathrm{l}$ of magnesium for a $\mathrm{pH}$ measured at 8.3. A small amount of sodium $(0.4 \mathrm{mmol} / \mathrm{l})$ originating from the starting material MgO was also measured. In the presence of sodium nitrate, the sodium or nitrate in solution at equilibrium with the M-S-H samples were similar as the initial solution used for the synthesis, indicating only a limited uptake of sodium or nitrate by the solid phases. However, such indirect determination of sodium and nitrate uptake based on the difference in concentration measurements and mass balance calculations are not very accurate at high alkali concentrations, as they are associated with a significant error, due to $10 \%$ relative error of the ionic chromatography measurements as discussed in (19). Thus, in addition a direct method (dissolution of the solid phase) is used in the section 3.3.

The addition of sodium nitrate lowered the $\mathrm{pH}$ from 8.3 to 7.7 at $\mathrm{Mg} / \mathrm{Si}=0.8$ and from 10 to 9.7 at $\mathrm{Mg} / \mathrm{Si}=1.2$ (Table 1 ). This decrease of the measured $\mathrm{pH}$ could be due to several factors, including the increase in ionic strength, the effect of $\mathrm{Na}^{+}$on the $\mathrm{pH}$ electrode (alkali error) and the uptake of more sodium than nitrate by the solid, which would release $\mathrm{H}^{+}$to the solution. The measured magnesium concentrations were slightly higher in the presence of sodium nitrate, which could indicate a partial substitution of magnesium by sodium as counter-ions at the negatively charged surface of M-S-H (25), as the magnesium concentrations are much lower than the sodium concentrations. More likely the increase of the Mg concentrations is due to the decrease $\mathrm{pH}$ which increases magnesium concentrations in equilibrium with M-S-H strongly as discussed in detail in $(25,40)$.

X-ray diffraction and ${ }^{29} \mathrm{Si}$ MAS-NMR spectroscopy showed that M-S-H was the main reaction product formed from $\mathrm{MgO}$ and $\mathrm{SiO}_{2}$ also in the presence of sodium nitrate. The presence of $\mathrm{NaNO}_{3}$, 
however, led to a repartition of the $\mathrm{Q}^{3}$ tetrahedral silicate sites as observed by ${ }^{29} \mathrm{Si}$ MAS-NMR spectroscopy as well as a small $\mathrm{pH}$ decrease and increase of magnesium in the solution which could indicate some replacement of magnesium at the cation exchange site at the M-S-H surface by sodium. These results were obtained at $20^{\circ} \mathrm{C}$ too.

\subsubsection{Effect of sodium hydroxide}

The addition of sodium hydroxide increases the $\mathrm{pH}$ of the solution, which results in brucite formation at higher magnesium contents and thus the study of the solids again focused on M-S-H with $\mathrm{Mg} / \mathrm{Si}=0.8$.

After 1 or 2 years equilibration at $20^{\circ} \mathrm{C}$ traces of brucite were detected by XRD only at high sodium hydroxide content ( $\geq 100 \mathrm{mmol} / \mathrm{l}$ ) (Figure 4 and Table 3 ). The intensity of the broad XRD signal at $19.7^{\circ} 2 \theta$ in the XRD patterns, which relates to signals from the main layers $(020,110)$, decreased in the presence of sodium hydroxide. Similarly to the addition of sodium nitrate, the shape of the hump at $\sim 60{ }^{\circ} 2 \theta$ was modified compared to the pure M-S-H and seemed shifted to higher angles. As for $\mathrm{NaNO}_{3}$, the layer-to-layer reflection (001) was observed at high sodium hydroxide concentration $([\mathrm{NaOH}]=500 \mathrm{mmol} / \mathrm{l})$ at $12.1 \AA$ A. This (001) reflection is usually visible at higher $\mathrm{Mg} / \mathrm{Si}$ $(24,25)$ in $\mathrm{M}-\mathrm{S}-\mathrm{H}$, which could indicate a rearrangement of magnesium resulting in structure containing less T:O:T layers but more T:O layers like in serpentine group minerals .

The weight loss data from TGA (Figure 5), indicates again an increase of the physically bound water (weight loss $30-250^{\circ} \mathrm{C}$ ) with the addition of sodium hydroxide as already observed in presence of sodium nitrate. 
The ${ }^{29} \mathrm{Si}$ MAS NMR spectra of the M-S-H samples, in Figure 6, indicates changes in the surrounding of the silicate layer structure in the presence of sodium hydroxide. The associated deconvolutions are detailed in Table 2. For pure $\mathrm{M}-\mathrm{S}-\mathrm{H}(\mathrm{Mg} / \mathrm{Si}=0.8)$ a small amount of unreacted silica is generally present, which is absent if sodium hydroxide was present. This is related to the increase of $\mathrm{pH}$ which destabilizes silica and has also been observed for $\mathrm{M}-\mathrm{S}-\mathrm{H}$ in the presence of calcium oxide, which also increase the $\mathrm{pH}(26)$. The content of $\mathrm{Q}^{3}$ tetrahedral sites decreased with the addition of sodium hydroxide. In particular, the content of $\mathrm{Q}^{3} \mathrm{c}$ was lowered while somewhat more $\mathrm{Q}^{3} \mathrm{a}$ environement was found at high sodium hydroxide content. As discussed above for $\mathrm{NaNO}_{3}$, the presence of more $\mathrm{Q}^{3} \mathrm{a}$ in the presence of high sodium concentrations could indicate a rearrangement of Mg resulting in structure containing less T:0:T layers but more T:0 layers. At $[\mathrm{NaOH}] \geq 100 \mathrm{mmol} / \mathrm{l}$, only the $\mathrm{Q}^{3} \mathrm{a}$ environment was observed.

The $\mathrm{Q}^{1}$ and $\mathrm{Q}^{2}$ contents increased with the addition of sodium hydroxide. The $\mathrm{Q}^{2}$ resonance was broadened with the increase of sodium hydroxide content (Figure 6) and an additional $\mathrm{Q}^{2}$ band at $\sim-83$ ppm was observed indicating the presence of sodium in the surrounding of silanol groups at the surface. The band at $-83 \mathrm{ppm}, \mathrm{Q}^{2} \mathrm{Na}$, increased up to $15 \% \pm 4 \%$ in the presence of $100 \mathrm{mmol} / \mathrm{l}$ $\mathrm{NaOH}$ as well as the $\mathrm{Q}^{2}$ tot $/ \mathrm{Q}^{3}$ tot indicating a depolymerization of the silicates in the presence of sodium hydroxide, while this effect was much weaker in the presence of sodium nitrate only. The observation of more $\mathrm{Q}^{3} \mathrm{a}$ and less $\mathrm{Q}^{3} \mathrm{c}$ (both at 20 and $50^{\circ} \mathrm{C}$, Table 2 ) could indicate the occurrence of more defects or vacancy in the silicate layers.

The presence of alkali hydroxide solution increases the $\mathrm{pH}$ strongly, which is expected to result in increased deprotonation of the silanol groups and thus in more negative charge at the surface. Highly negative charge at silanol groups limits the growth or assembly of silicate sheets as suggested in (25). The data presented above showed that at high $\mathrm{pH}$ values, i.e. in sodium hydroxide solutions, sodium is present in the vicinity of the tetrahedral silicates and more defects are present in the 
silicate sheets; an effect which was hardly observed in $\mathrm{NaNO}_{3}$ solutions. The presence of sodium hydroxide, however, did not significantly change the structure of M-S-H although at high concentrations a depolymerisation of the silica has been observed. Similarly, for synthetic C-S-H a shortening of the silicate chains at high $\mathrm{pH}$ was reported $(19,41)$.

The M-S-H samples in absence and presence of $\mathrm{NaOH}$ were also characterized by X-ray pair distribution function (PDF) analysis (Figure 7). The peaks of M-S-H in the absence of $\mathrm{NaOH}$ were tentatively assigned using the structures of talc and antigorite as references $(42,43)$; they mainly corresponded to $\operatorname{Mg}-\operatorname{Mg}(r=3.13 \AA, 5.36 \AA, 8.21 \AA, 9.42 \AA, 11.06 \AA)$ and Mg-O (2.09 $\AA$ ) distances within the same layer as well as $\mathrm{Si}-\mathrm{Si}(3.20 \AA)$ and $\mathrm{Si}-0$ distances in tetrahedral silicate layer ( $\mathrm{r}=1.61 \AA$ ) as already reported in (25). M-S-H exhibited a rather short coherence length, close to $12 \AA$ indicating a poorly crystalline nature and the nano-sized particles as previously discussed $(24,25,44)$. The X-ray PDF analyses of the M-S-H samples with $\mathrm{NaOH}$ were very similar to the one of M-S-H prepared in the absence of alkalis regardless of the amount of $\mathrm{NaOH}$ present. This confirms that the sodium uptake in the solid phase occurs only in the exchangeable site of the deprotonated silanol groups. Also, the coherent lengths measured by the X-ray PDF analysis are very similar for all samples. Although ${ }^{29}$ Si MAS NMR indicates that sodium uptake decreases the polymerization of the silicate sheets it has no effect on the coherent size of the M-S-H sheets of about $12 \AA$.

The solution compositions of the samples synthetized in the presence of sodium hydroxide during 2 years at $20^{\circ} \mathrm{C}$ are detailed in Table 3 . The addition of sodium hydroxide to $\mathrm{M}-\mathrm{S}-\mathrm{H}$ increased the $\mathrm{pH}$ value from 8.3 in the solution of pure $\mathrm{M}-\mathrm{S}-\mathrm{H}$ to $\mathrm{pH} 13.3$ in the presence of $500 \mathrm{mmol} / \mathrm{l} \mathrm{NaOH}$. The silicon concentration increased from $1.4 \mathrm{mmol} / \mathrm{l}$ at $\mathrm{pH} 8.3$ to $35 \mathrm{mmol} / \mathrm{l}$ at $\mathrm{pH} 13.3$; however, the silicon concentration remained below the concentration in equilibrium with respect to 
amorphous silica above $\mathrm{pH}$ 9. The magnesium concentration increased from $0.4 \mathrm{mmol} / \mathrm{l}$ with the addition of $\mathrm{NaOH}$ up to $9.9 \mathrm{mmol} / \mathrm{l}$ at $\mathrm{pH} 12.5$ in the absence of any brucite. At even higher pH values the formation of brucite lowered the magnesium concentration to $<0.06 \mathrm{mmol} / \mathrm{l}$. The relative high magnesium concentrations observed between $\mathrm{pH} 10$ to 12.5 could possibly be related to the presence of aqueous magnesium silica complexes, which had not yet been described in literature.

The measured sodium concentrations were considerably lower than what was initially added. Around $80 \%$ of sodium was not found in the solution containing originally $10 \mathrm{mmol} / \mathrm{l} \mathrm{NaOH}$ and thus might be associated with M-S-H; either incorporated or in the diffuse layer. Up to $50 \mathrm{mmol} / \mathrm{l}$ of sodium were taken up in the M-S-H phase at higher $\mathrm{NaOH}$ concentrations, in agreement with the ${ }^{29} \mathrm{Si}$ MAS NMR data which shows the presence of sodium in the neighboring of the silicates. The sodium in the solid could be i) adsorbed on M-S-H surface to compensate the negative surface charge (either in the Stern layer near the surface or in the diffuse layer; which both are partitioned with the solid during filtration), ii) in the octahedral layer substituting magnesium, which will be further investigated in the section 3.3 or iii) still be present due to insufficient washing; this last point will be excluded by the CEC results (section 3.2).

\subsection{Surface charge and cation exchange}

This part focuses on the results of the cation exchange capacity (CEC) measurements. These measurements had been carried out on the solid phases after filtration, washing and drying. The CECs measured on the samples synthesized in 0,10 and $100 \mathrm{mmol} / \mathrm{l}$ sodium nitrate or sodium hydroxide solution are shown in Figure 8. A positive CEC of $35 \mathrm{meq} / 100 \mathrm{~g}$ is measured for M-S-H without additional sodium, indicating the presence of exchangeable cations and thus a negative surface charge of M-S-H comparable to phyllosilicates. The kind and amount of cations present on the CEC sites have also been determined; mainly magnesium was observed plus 1 to $2 \%$ sodium. 
The presence of only 1 to $2 \%$ of $\mathrm{Na}^{+}$on the surface sites, although similar magnesium and sodium concentrations in solution were measured (Table 1), shows that the sorption of the bivalent $\mathrm{Mg}^{2+}$ is strongly favored compared to the monovalent $\mathrm{Na}^{+}$. The total amount of magnesium at the cation exchange sites in the sample without $\mathrm{NaOH}$ is with $0.022 \mathrm{Mg} / \mathrm{Si}$ relatively low as also discussed in (25). Thus only 2 to $3 \%$ of the total magnesium is present on the cation exchange sites of M-S-H, while $97-98 \%$ is in the main magnesium oxide layer.

In the presence of $\mathrm{NaOH}$ or $\mathrm{NaNO}_{3}$ the CEC measurements showed the progressive replacement of magnesium at the surface by sodium in agreement with the observations by ${ }^{29} \mathrm{Si}$ MAS NMR spectroscopy $\left(Q^{3} a, b>Q^{3} c\right)$.

In $\mathrm{NaNO}_{3}$ solution, a CEC of $31 \mathrm{meq} / 100 \mathrm{~g}, 30 \mathrm{meq} / 100 \mathrm{~g}$ and $34 \mathrm{meq} / 100 \mathrm{~g}$ was measured in the 10,50 , and $100 \mathrm{mmol} / \mathrm{l} \mathrm{NaNO}_{3}$ samples, respectively, comparable to the $35 \mathrm{meq} / 100 \mathrm{~g}$ of pure M-S-H (Figure 8a). At $10 \mathrm{mmol} / \mathrm{l} \mathrm{NaNO}_{3}$ where $1 \mathrm{mmol} / \mathrm{l}$ magnesium and $9 \mathrm{mmol} / \mathrm{l}$ sodium were present in the solution, 20 meq/100g of magnesium and $10 \mathrm{meq} / 100 \mathrm{~g}$ of sodium were found on the cation exchange sites indicating again a higher preference of the silanol surface groups for the bivalent magnesium than the monovalent sodium, in agreement with observations on silica (45-47). At higher sodium concentration, most of the cation exchange sites are occupied by sodium due to its very large concentration compared to magnesium.

In the presence of sodium hydroxide, where the $\mathrm{pH}$ increased, an increase of the CEC was observed. The total CEC of the $10 \mathrm{mmol} / \mathrm{l} \mathrm{NaOH}$ sample increased slightly to $41 \mathrm{meq} / 100 \mathrm{~g}$, while the CEC in $100 \mathrm{mmol} / \mathrm{l} \mathrm{NaOH}$ was measured at $170 \mathrm{meq} / 100 \mathrm{~g}$ (Figure 8b). The high CEC measured in $100 \mathrm{mmol} / \mathrm{l} \mathrm{NaOH}$ sample was confirmed by the large increase of sorbed sodium (Figure 8). The 10 $\mathrm{mmol} / \mathrm{l} \mathrm{NaOH}$ sample contained more exchangeable sodium than magnesium which might be due to the lower magnesium concentration $\left(0.25 \mathrm{mmol} / \mathrm{l}\right.$ compared to $1.3 \mathrm{mmol} / \mathrm{l}$ in the $10 \mathrm{mmol} / \mathrm{l} \mathrm{NaNO}_{3}$ 
sample). In $100 \mathrm{mmol} / \mathrm{l} \mathrm{NaOH}$, where more sodium was present, most of the magnesium at the surface was replaced by sodium (Figure 8b). As also magnesium concentration in solution is very low, the magnesium is in the presence of $\mathrm{NaOH}$ redistributed from the surface sites to the octahedral layer of M-S-H. The observed increase of surface sites at higher $\mathrm{pH}$ values agrees with the observation in plain M-S-H (25), where a continuous increase of CEC was measured from $\mathrm{pH} 8$ to $\mathrm{pH}$ 10. These observations are consistent with a higher negative surface charge at higher $\mathrm{pH}$ values due to the deprotonation of the silanol surface groups at increasing $\mathrm{pH}$ as observed for $\mathrm{M}-\mathrm{S}-\mathrm{H}(25)$ and for silica (45-47).

Finally, the good correlation between the CEC measured by colorimetry (black dots in Figure 8) and the total of cations released by the cobalt(III) replacement (indicated by the heights of the bars in Figure 8) indicates no significant dissolution of the phases. However, at very $100 \mathrm{mmol} / \mathrm{l} \mathrm{Na}$, more sodium in solution is observed than measured by colorimetry. The pH value of the CEC solution before the exchange was about 6.5, while after the CEC exchange $\mathrm{pH}$ values between 9 to 11 were measured, considerably lower than the original $\mathrm{pH}$ of the sample (Table 3). No residual salts formation during the drying was observed. Thus a subset of the samples with originally $50 \mathrm{mmol} / \mathrm{l}$ and $100 \mathrm{mmol} / \mathrm{l} \mathrm{NaOH}$ were also equilibrated with water to check for possible dissolution and the pH effect. No relevant dissolution of M-S-H was observed $([\mathrm{Mg}]<0.1 \mathrm{mmol} / \mathrm{l}$, and $[\mathrm{Si}]<0.5 \mathrm{mmol} / \mathrm{l})$. However, $~ 10-15 \%$ of the sodium measured by CEC was released in this $\mathrm{H}_{2} \mathrm{O}$ solution as the lowering of $\mathrm{pH}$ lowered the negative surface charge and thus its ability to bind Na. Thus the slightly higher total of cations of $170 \mathrm{meg} / \mathrm{l}$ measured corresponds to the amount of ions bound at $\mathrm{pH} 12.5$, while the lower 155 meq/l measured by colorimetry represent the CEC at pH 11 . As the difference in $\mathrm{pH}$ in the original and measurement solutions are lower in the other samples, these differences are also lower. 
The zeta potential measures the charge of a particle not directly at the surface but in some distance and are thus influence by the presence of dissolved ions and ionic strength $(34,35,48)$. The zeta potential measurements of $\mathrm{M}-\mathrm{S}-\mathrm{H}$ in the absence of alkali is $-19 \mathrm{mV}$ as shown in Figure 9a. This negative effective charge of M-S-H is consistent with the CEC data presented above and probably related to the partial deprotonation of the $\mathrm{Si}-\mathrm{OH}$ groups at $\mathrm{pH} 8.6$ as discussed previously in (25). The zeta potential measured for the M-S-H 0.8 samples synthesized in sodium nitrate or sodium hydroxide are plotted versus the pH measured in suspension in Figure 9a. It should be noted that an increase of the ionic strength due to the addition of sodium nitrate or sodium hydroxide shrinks the electric double layer which results in a less negative zeta potential measurements (49-51) even if the charge at the surface remains constant. To limit that effect, the zeta potential was measured only in the suspensions where the initial sodium concentration was lower or equal to $50 \mathrm{mmol} / \mathrm{l}$.

The effective charge of M-S-H samples in sodium nitrate was negative with zeta potential values of $-19 \pm 2 \mathrm{mV}$ similar to the pure M-S-H. The observed relatively constant values are consistent with the relatively constant $\mathrm{pH}$ values and a similar content of $\mathrm{Q}^{1}$ and $\mathrm{Q}^{2}$ sites in the silicate layers. The negative effective charge comparable to M-S-H in water is consistent with the observed limited sodium adsorption in the presence of sodium nitrate.

Sample with $10 \mathrm{mmol} / \mathrm{l}$ of sodium hydroxide showed a strong drop of zeta potential value down to $-65 \pm 6 \mathrm{mV}$ due to the increase of $\mathrm{pH}$ which further deprotonates of the silanol groups. At higher sodium hydroxide concentrations, the zeta potential re-increased up to around $-20 \pm 5 \mathrm{mV}$, although the $\mathrm{pH}$ was even higher, 10.2 and 11.8 for 25 and $50 \mathrm{mmol} / \mathrm{l} \mathrm{NaOH}$. The measured zeta potential, which does not measure the charge directly at the surface, but the potential at some distance to the surface, is thus the result of several opposing effects: decreased by the higher negative surface charge at higher $\mathrm{pH}$ values, increased by the stronger attraction of cations to the negative 
surface (which is also visible by the increase in CEC), by the presence of more dissolved $\mathrm{Mg}^{2+}$ and by the higher ionic strength. These competing effects make the result difficult to interpret.

A second set of zeta potential experiments was performed on a suspension of $\mathrm{M}-\mathrm{S}-\mathrm{H} 0.8$ synthesized in $10 \mathrm{mmol} / \mathrm{l} \mathrm{NaOH}$ as detailed in Figure 9b. Initially, the zeta potential was measured at $-65 \pm 7 \mathrm{mV}$, as reported also in Figure 9a. A mixed solution of magnesium chloride and magnesium hydroxide was added to the suspension to add magnesium without changing the pH significantly. An increase of the zeta potential was measured with the addition of dissolved magnesium until $-30 \mathrm{mV}$ $\pm 6 \mathrm{mV}$ for $0.83 \mathrm{mmol} / \mathrm{l}$ of magnesium measured in solution and a $\mathrm{pH}$ of 9.1 . Then, a solution of $\mathrm{NaOH}$ $(\mathrm{pH} \sim 11)$ was added to the suspension. The zeta potential measured dropped down to $-76 \pm 15 \mathrm{mV}$ together with the concentration of magnesium, mainly due to the $\mathrm{pH}$ increase up to 10.6. Mixed magnesium chloride and hydroxide solution was added again, resulting in another increase of the zeta potential measured to $-27 \pm 6 \mathrm{mV}$ for a $\mathrm{pH}$ at 9.4 and $25 \mathrm{mmol} / \mathrm{l}$ of sodium and $7.8 \mathrm{mmol} / \mathrm{l}$ of magnesium. This experiment illustrates the coupled effect of both $\mathrm{pH}$, which results in a more negative zeta potential, and $\mathrm{Mg}^{2+}$ concentration, which compensates the negative surface charge by being present very near the surface.

The ${ }^{29} \mathrm{Si}$ MAS NMR spectroscopy has shown a higher content of $\mathrm{Q}^{1}$ and $\mathrm{Q}^{2}$ tetrahedral silicate sites in the presence of sodium hydroxide. These silicate sites can also be deprotonated at high $\mathrm{pH}$ values resulting in a more negative surface charge, as had been visible in the measured increase of the cation exchange sites at higher $\mathrm{pH}$ values (Figure 8). The combined CEC results and zeta potential data indicate a more negative surface charge at higher $\mathrm{pH}$ values and the presence of more cations near the surface to compensate the negative charge of the silicate sites. 


\subsection{Alkali uptake by M-S-H and effect of the measurements}

It was found by CEC measurements that alkali ions can be present at exchangeable sites of M$\mathrm{S}-\mathrm{H}$ and that their amount increases at higher $\mathrm{pH}$ where more silanol groups are deprotonated. In this section we investigate the possible uptake of alkali in non-exchangeable sites by comparing the results from different methods.

The total uptake of alkali has been obtained by different methods: by

1) the indirect method based on massbalance, where the alkalis in solution after the filtration are subtracted from the initial alkali content,

2) the direct method, where a part of the solid, after washing, is completely re-dissolved

In all these methods, alkalis in the diffuse layer will also be included as they remain with the solid during filtration, such that the measured values include alkalis present in the diffuse, in the Stern layer and on cation exchange sites (36). The washing (Milli-Q/ethanol and ethanol) applied before the direct and the CEC method could potentially lead to lower alkali content as the washing might eliminate some of the cations in the diffuse layer as detailed in (19). The direct and indirect method will include cations present in the main layer as well as on the surface, while the CEC method will only include the cations at surface.

Figure 10a shows that at low alkali concentrations ( $\leq 100 \mathrm{mmol} / \mathrm{l}$ sample $)$ and when the uptake is significant, the three methods give comparable results, indicating

i) that the indirect method is sufficiently precise (Figure 10a) at lower concentrations

ii) that little loosely bound cations are in the diffuse layer (as the washing did not remove a significant fraction) and 
iii) that the alkalis are mainly present at the surface and no/or very little in the octahedral main layer.

At high alkali concentrations however, the indirect method is associated with a larger relative error due to the error of the solution measurement. In the presence of $\mathrm{NaNO}_{3}$, the error of the indirect method was too large to capture the low small sodium uptake, and the alkali uptakes were obtained from the direct method as reported in Figure 10a.

The content of sodium in the solid is generally low in the presence of $\mathrm{NaNO}_{3}$ and increases only very moderately from $\mathrm{Na} / \mathrm{Si}=0$ to 0.04 . In the presence of hydroxide and at high $\mathrm{pH}$ values, the $\mathrm{Na} / \mathrm{Si}, \mathrm{K} / \mathrm{Si}$, and $\mathrm{Li} / \mathrm{Si}$ increased much more strongly. A maximum alkali/Si of 0.2 was observed at $100 \mathrm{mmol} / \mathrm{l}$ alkali addition and no significant effect of the $\mathrm{Mg} / \mathrm{Si}$ or of the kind of alkali $(\mathrm{Na}, \mathrm{K}, \mathrm{Li}$ ) was observed, in agreement with the findings reported in (21) as also shown in Figure 10b. This higher alkali uptake in the presence of hydroxide confirmed the findings from ${ }^{29}$ Si MAS NMR and increase observed by the CEC data presented above.

The CEC data and the indirect method gave similar $\mathrm{Na}_{\text {exch }} / \mathrm{Si}$ as the direct method based on total dissolution (Figure 10), which confirms that sodium is present in M-S-H only at the surface sites. The CEC does not allow distinguishing clearly between specifically sorbed cations at the surface and charge balancing cations present in the diffuse layer; the comparable uptake of $\mathrm{Na}, \mathrm{K}$ and Li tends to indicate that the alkali ions are mainly present as exchangeable cations in the Stern and diffuse layers.

Similar observations have been made for alkali uptake by C-S-H phases, an increase of the uptake at higher alkali concentrations as well as at higher $\mathrm{pH}$ values (41). Similar to M-S-H, C-S-H has also a negative surface charge, which becomes more negative at higher $\mathrm{pH}$ resulting in a higher 
cation binding at higher $\mathrm{pH}$. Additionally, the alkali to silica ratio on M-S-H is comparable to the alkali to silica ratio measured on low $\mathrm{Ca} / \mathrm{Si} \mathrm{C}-\mathrm{S}-\mathrm{H}$. In contrast to $\mathrm{M}-\mathrm{S}-\mathrm{H}$, however, a clear decrease of alkali uptake is observed at increasing $\mathrm{Ca} / \mathrm{Si}$ in $\mathrm{C}-\mathrm{S}-\mathrm{H}$. The presence of high dissolved $\mathrm{Ca}^{2+}$ concentrations leads to strongly positive zeta potential measurements in $\mathrm{C}-\mathrm{S}-\mathrm{H}$ as $\mathrm{Ca}^{2+}$ shows a very high affinity to silanol surface sites, which suppresses the sorption of monovalent alkali ions (49).

\section{Conclusions}

The effect of alkali on the structure of M-S-H was studied as well the potential of M-S-H to bind alkalis. The amount of alkalis bound in $\mathrm{M}-\mathrm{S}-\mathrm{H}$ affects the $\mathrm{pH}$ of the surrounding solution, thus concentration of many other elements and the durability of cements where M-S-H is present.

The presence of sodium nitrate or sodium hydroxide did not significantly change the structure of M-S-H. Only at high sodium hydroxide concentrations ( $\geq 100 \mathrm{mmol} / \mathrm{l})$ a higher fraction of $\mathrm{Q}^{1}$ and $\mathrm{Q}^{2}$ tetrahedral silicate sites was observed, indicating a depolymerisation of the silica sheets present in M-S-H.

In the presence of sodium nitrate, at $\mathrm{pH}$ values ranging 7 to 8 , only a very limited sodium uptake was observed with maximal molar alkali/Si ratios of $0.04 \pm 0.02$ in $100 \mathrm{mmol} / \mathrm{l}$ alkali.

Much higher alkali uptake was observed at high $\mathrm{pH}$ values in the presence of sodium hydroxide as higher $\mathrm{pH}$ values deprotonated the silanol surface sites further leading to more negatively charged surface. This increased the number of cation exchange sites measured at higher pH values and the 
ability of M-S-H to sorb alkali. In the absence of alkali, approximately $2 \%$ of the total magnesium was bound in exchangeable sites at the M-S-H surface, while $98 \%$ where present within the M-S-h main layers. These surface sites showed a strong preference of $\mathrm{Mg}^{2+}$ over $\mathrm{Na}^{+}$and only at very high $\mathrm{Na}^{+} / \mathrm{Mg}^{2+}$ in solution, the magnesium originally present as exchangeable cation was progressively replaced by the alkalis. The molar $\mathrm{Na} / \mathrm{Si}$ ratio in $\mathrm{M}-\mathrm{S}-\mathrm{H}$ raised from 0.03 in $10 \mathrm{mmol} / \mathrm{l} \mathrm{NaOH}$ to $\sim 0.2$ in $100 \mathrm{mmol} / \mathrm{l} \mathrm{NaOH}$, while the amount of Mg present on surface sites decreased.

The comparison of different methods indicated that alkalis were present as exchangeable cations at the surface or interlayer of M-S-H, but not to a significant extent within the magnesium and silicate sheets. For $\mathrm{KOH}$ and $\mathrm{LiOH}$ a comparable uptake as for $\mathrm{NaOH}$ was observed.

The limited experimental evidence available shows no strong influence of $\mathrm{Mg} / \mathrm{Si}$ on alkali uptake (Figure 10, (21)). It can be speculated that the alkali uptake by M-S-H could be similar at high $\mathrm{Mg} / \mathrm{Si}$ as the CEC and the measured zeta potential hardly vary with the $\mathrm{Mg} / \mathrm{Si}$ and as the concentration of magnesium remain low also at a high $\operatorname{Mg} / \operatorname{Si}(25,26,40)$, which limits the competition of dissolved magnesium with alkali sorption. Thus M-S-H could expect to bind also other cations. However, the presence of calcium, another divalent cation, which is present in higher concentration than magnesium in cement pore solutions (52), might suppress the sorption of monovalent cations as calcium is preferentially bound on the surface of M-S-H as observed in (26). Also, other cations could sorbed on M-S-H. As M-S-H is stable also at $\mathrm{pH}$ values below 10 , where cement hydrates are destabilized (53), the sorption properties of M-S-H for different cations could be of interest for the long-term performance of nuclear waste repositories. 


\section{Acknowledgements}

The authors would like to thank Alexandre Dauzères and the French Institute of Radiation Protection and Nuclear Safety for the Ellina Bernard's Ph.D. funding; Daniel Rentsch for helpful discussions. The NMR hardware was partially granted by the Swiss National Science Foundation (SNSF, grant no. 206021_150638/1).

\section{References}

1. De Weerdt K, Justnes H. The effect of sea water on the phase assemblage of hydrated cement paste. Cement and Concrete Composites. 2015;55:215-22.

2. Jakobsen UH, De Weerdt K, Geiker MR. Elemental zonation in marine concrete. Cement and Concrete Research. 2016;85:12-27.

3. Tumidajski PJ, Chan G. Durability of high performance concrete in magnesium brine. Cement and concrete research. 1996;26(4):557-65.

4. Bonen D, Cohen MD. Magnesium sulfate attack on portland cement paste-II. Chemical and mineralogical analyses. Cement and Concrete Research. 1992;22(4):707-18.

5. Gollop R, Taylor H. Microstructural and microanalytical studies of sulfate attack. I. Ordinary Portland cement paste. Cement and Concrete Research. 1992;22(6):1027-38.

6. Santhanam M, Cohen MD, Olek J. Mechanism of sulfate attack: a fresh look: part 1: summary of experimental results. Cement and concrete research. 2002;32(6):915-21.

7. Gaucher EC, Blanc P. Cement/clay interactions-a review: experiments, natural analogues, and modeling. Waste Management. 2006;26(7):776-88.

8. Savage D, Walker C, Arthur R, Rochelle C, Oda C, Takase H. Alteration of bentonite by hyperalkaline fluids: A review of the role of secondary minerals. Physics and Chemistry of the Earth, Parts A/B/C. 2007;32(1):287-97.

9. Dauzères A, Le Bescop P, Sardini P, Cau Dit Coumes C. Physico-chemical investigation of clayey/cement-based materials interaction in the context of geological waste disposal: Experimental approach and results. Cement and Concrete Research. 2010;40(8):1327-40.

10. Jin F, Al-Tabbaa A. Thermogravimetric study on the hydration of reactive magnesia and silica mixture at room temperature. Thermochimica Acta. 2013;566:162-8.

11. Jin F, Al-Tabbaa A. Strength and hydration products of reactive MgO-silica pastes. Cem Concr Comp. 2014;52:27-33.

12. Temuujin J, Okada K, MacKenzie K. Role of water in the mechanochemical reactions of MgO-SiO 2 systems. Journal of Solid State Chemistry. 1998;138(1):169-77.

13. Vandeperre L, Liska M, Al-Tabbaa A. Microstructures of reactive magnesia cement blends. Cement and Concrete Composites. 2008;30(8):706-14. 
14. Vandeperre L, Liska M, Al-Tabbaa A. Hydration and mechanical properties of magnesia, pulverized fuel ash, and portland cement blends. Journal of materials in civil engineering. 2008;20(5):375-83.

15. Wei J, Yu Q, Zhang $\mathrm{W}$, Zhang $\mathrm{H}$. Reaction products of $\mathrm{MgO}$ and microsilica cementitious materials at different temperatures. Journal of Wuhan University of Technology-Mater Sci Ed. 2011;26(4):745-8.

16. Zhang $\mathrm{T}$, Cheeseman $\mathrm{C}$, Vandeperre L. Development of low $\mathrm{pH}$ cement systems forming magnesium silicate hydrate (MSH). Cement and Concrete Research. 2011;41(4):439-42.

17. Walling SA, Kinoshita H, Bernal SA, Collier NC, Provis JL. Structure and properties of binder gels formed in the system $\mathrm{Mg}(\mathrm{OH})_{2}-\mathrm{SiO}_{2}-\mathrm{H}_{2} \mathrm{O}$ for immobilisation of Magnox sludge. Dalton Transactions. 2015;44(17):8126-37.

18. Zhang T, Vandeperre LJ, Cheeseman CR. Magnesium-silicate-hydrate cements for encapsulating problematic aluminium containing wastes. Journal of Sustainable Cement-Based Materials. 2012;1(12):34-45.

19. L'Hôpital E, Lothenbach B, Scrivener K, Kulik D. Alkali uptake in calcium alumina silicate hydrate (CASH). Cement and Concrete Research. 2016;85:122-36.

20. Stade H. On the reaction of CSH (di, poly) with alkali hydroxides. Cement and Concrete Research. 1989;19(5):802-10.

21. Brew D, Glasser F. The magnesia-silica gel phase in slag cements: alkali (K, Cs) sorption potential of synthetic gels. Cement and Concrete Research. 2005;35(1):77-83.

22. Lerouge $\mathrm{C}$, Gaboreau S, Grangeon S, Claret F, Warmont F, Jenni A, et al. In situ interactions between Opalinus Clay and Low Alkali Concrete. Physics and Chemistry of the Earth, Parts A/B/C. 2017;99:3-21.

23. Nied D, Enemark-Rasmussen K, L'Hopital E, Skibsted J, Lothenbach B. Properties of magnesium silicate hydrates (MSH). Cement and Concrete Research. 2016;79:323-32.

24. Roosz C, Grangeon S, Blanc P, Montouillout V, Lothenbach B, Henocq P, et al. Crystal structure of magnesium silicate hydrates (MSH): The relation with 2: $1 \mathrm{Mg}-\mathrm{Si}$ phyllosilicates. Cement and Concrete Research. 2015;73:228-37.

25. Bernard E, Lothenbach $B$, Chlique $C$, Wyrzykowski $M$, Dauzères $A$, Pochard I, et al. Characterization of magnesium silicate hydrate (M-S-H). Cement and Concrete Research. 2019;116:30930.

26. Bernard E, Lothenbach B, Cau-Dit-Coumes C, Chlique C, Dauzères A, Pochard I. Magnesium and calcium silicate hydrates, Part I: Investigation of the possible magnesium incorporation in calcium silicate hydrate (C-S-H) and of the calcium in magnesium silicate hydrate (M-S-H). Applied Geochemistry. 2018;89:229-42.

27. Bernard E, Lothenbach B, Rentsch D, Pochard I, Dauzères A. Formation of magnesium silicate hydrates (M-S-H). Physics and Chemistry of the Earth, Parts A/B/C. 2017;99:142-57.

28. Meral C, Benmore C, Monteiro PJ. The study of disorder and nanocrystallinity in C-S-H, supplementary cementitious materials and geopolymers using pair distribution function analysis. Cement and Concrete Research. 2011;41(7):696-710.

29. White CE, Provis JL, Bloomer B, Henson NJ, Page K. In situ X-ray pair distribution function analysis of geopolymer gel nanostructure formation kinetics. Physical Chemistry Chemical Physics. 2013;15(22):8573-82.

30. Egami T, Billinge SJL. Chapter 3. The method of total scattering and atomic pair distribution function analysis: Pergamon Materials Series; 2003. 
31. Qiu X, Thompson JW, Billinge SJ. PDFgetX2: a GUI-driven program to obtain the pair distribution function from X-ray powder diffraction data. Journal of Applied Crystallography. 2004;37(4):678-.

32. Farrow C, Juhas P, Liu J, Bryndin D, Božin E, Bloch J, et al. PDFfit2 and PDFgui: computer programs for studying nanostructure in crystals. Journal of Physics: Condensed Matter. 2007;19(33):335219.

33. Massiot D, Fayon F, Capron M, King I, Le Calvé S, Alonso B, et al. Modelling one-and twodimensional solid-state NMR spectra. Magnetic Resonance in Chemistry. 2002;40(1):70-6.

34. James M, Hunter RJ, O'Brien RW. Effect of particle size distribution and aggregation on electroacoustic measurements of. zeta. potential. Langmuir. 1992;8(2):420-3.

35. Kaya A, Yukselen Y. Zeta potential of clay minerals and quartz contaminated by heavy metals. Canadian Geotechnical Journal. 2005;42(5):1280-9.

36. Plusquellec G, Nonat A. Interactions between calcium silicate hydrate (CSH) and calcium chloride, bromide and nitrate. Cement and Concrete Research. 2016;90:89-96.

37. Mägi M, Lippmann E, Samoson A, Engelhardt G, Grimmer AR. Solid-state high-resolution silicon29 chemical shifts in silicates. The Journal of Physical Chemistry. 1984;88:1518-22.

38. MacKenzie K, Meinhold R. The thermal reactions of talc studied by 29 Si and 25 Mg MAS NMR. Thermochimica Acta. 1994;244:195-203.

39. MacKenzie KJD, Meinhold RH. Thermal reaction of chrysotile revisited: a ${ }^{29} \mathrm{Si}$ and ${ }^{25} \mathrm{Mg}$ NMR study. American Mineralogist. 1994;79:43-50.

40. Bernard E, Lothenbach B, Le Goff F, Pochard I, Dauzères A. Effect of magnesium on calcium silicate hydrate (C-S-H). Cement and Concrete Research. 2017;97:61-72.

41. Lothenbach B, Nonat A. Calcium silicate hydrates: Solid and liquid phase composition. Cement and Concrete Research. 2015;78:57-70.

42. Gruner JW. The crystal structures of talc and pyrophyllite. Zeitschrift für KristallographieCrystalline Materials. 1934;88(1-6):412-9.

43. Dódony I, Pósfai M, Buseck PR. Revised structure models for antigorite: An HRTEM study. American Mineralogist. 2002;87(10):1443-57.

44. Chiang W-S, Ferraro G, Fratini E, Ridi F, Yeh Y-Q, Jeng U, et al. Multiscale structure of calcium-and magnesium-silicate-hydrate gels. J Mater Chem A. 2014;2(32):12991-8.

45. de Lara LS, Rigo VA, Michelon MF, Metin CO, Nguyen QP, Miranda CR. Molecular dynamics studies of aqueous silica nanoparticle dispersions: salt effects on the double layer formation. Journal of Physics: Condensed Matter. 2015;27(32):325101.

46. Bruzzoniti MC, De Carlo RM, Fiorilli S, Onida B, Sarzanini C. Functionalized SBA-15 mesoporous silica in ion chromatography of alkali, alkaline earths, ammonium and transition metal ions. Journal of Chromatography A. 2009;1216(29):5540-7.

47. Skluzacek JM, Tejedor MI, Anderson MA. An iron-modified silica nanofiltration membrane: Effect of solution composition on salt rejection. Microporous and mesoporous materials. 2006;94(1):288-94.

48. Giese JRF, Wu W, Van Oss CJ. Surface and electrokinetic properties of clays and other mineral particles, untreated and treated with organic or inorganic cations. Journal of dispersion science and technology. 1996;17(5):527-47.

49. Labbez C, Nonat A, Pochard I, Jönsson B. Experimental and theoretical evidence of overcharging of calcium silicate hydrate. Journal of Colloid and Interface Science. 2007;309(2):303-7. 
50. Oćwieja M, Adamczyk Z, Morga M, Michna A. High density silver nanoparticle monolayers produced by colloid self-assembly on polyelectrolyte supporting layers. Journal of colloid and interface science. 2011;364(1):39-48.

51. Oćwieja M, Adamczyk Z, Kubiak K. Tuning properties of silver particle monolayers via controlled adsorption-desorption processes. Journal of colloid and interface science. 2012;376(1):1-11.

52. Vollpracht A, Lothenbach B, Snellings R, Haufe J. The pore solution of blended cements: a review. Materials and Structures. 2015:1-27.

53. Leisinger SM, Bhatnagar A, Lothenbach B, Johnson CA. Solubility of chromate in a hydrated OPC. Applied Geochemistry. 2014;48:132-40.

Tables:

Table 1: Measured $\mathrm{pH}$ values and dissolved concentrations in the solutions in equilibrium with the M-S-H synthesized in the presence of sodium nitrate (at 20 and $50^{\circ} \mathrm{C}$, curing time: 1 or 2 years)

\begin{tabular}{|c|c|c|c|c|c|c|c|}
\hline & $\mathrm{Mg} / \mathrm{Si}$ & $\begin{array}{c}{\left[\mathrm{NaNO}_{3}\right]_{\text {init- }}} \\
\text { theo } \\
\mathrm{mmol} / \mathrm{l}\end{array}$ & $\mathrm{pH}$ & {$[\mathrm{Na}]$} & $\begin{array}{r}{\left[\mathrm{NO}_{3}\right]} \\
\mathrm{m}\end{array}$ & [Mg] & [Si] \\
\hline \multirow[t]{7}{*}{$20^{\circ} \mathrm{C}$} & & 0 & 8.3 & 0.4 & --- & 0.4 & 1.4 \\
\hline & & 10 & 8.1 & 9.1 & 10.4 & 1.3 & 1.4 \\
\hline & & 25 & 8.1 & 22.8 & 25.9 & 1.9 & 1.4 \\
\hline & 0.8 & 50 & 8 & 47.8 & 53.6 & 2.8 & 1.4 \\
\hline & & 100 & 7.7 & 107 & 95.1 & 4.3 & 1.2 \\
\hline & & 250 & 7.6 & 251 & 236 & 5.1 & 1.0 \\
\hline & & 500 & 7.7 & 495 & 471 & 5.9 & 1.2 \\
\hline \multirow[t]{5}{*}{$20^{\circ} \mathrm{C}$} & & 0 & 10 & 0.5 & --- & 0.1 & 0.008 \\
\hline & & 10 & 10 & 9 & 10.4 & 0.8 & 0.002 \\
\hline & 1.2 & 25 & 9.8 & 23.4 & 26.1 & 1.3 & 0.001 \\
\hline & & 50 & 9.8 & 48.4 & 53.2 & 1.8 & $<0.001$ \\
\hline & & 100 & 9.7 & 99.1 & 88.9 & 2.9 & 0.002 \\
\hline \multirow[t]{7}{*}{$50^{\circ} \mathrm{C}$} & & 0 & 8.3 & 0.3 & --- & 0.10 & 2.6 \\
\hline & & 10 & 8.1 & 4.8 & 5.3 & 0.8 & 2.6 \\
\hline & & 25 & 8.0 & 23.5 & 27.4 & 1.3 & 2.5 \\
\hline & 0.8 & 50 & 7.9 & 49.7 & 54.2 & 1.9 & 2.6 \\
\hline & & 100 & 7.9 & 95.6 & 105.6 & 2.8 & 2.5 \\
\hline & & 250 & 7.8 & 261.3 & 282.0 & 2.9 & 2.5 \\
\hline & & 500 & 7.7 & 512.7 & 553.3 & 2.3 & 2.3 \\
\hline
\end{tabular}


Table 2: Peak shifts and relative intensities (quantifications) of different silicon shifts obtained from the deconvolution of the ${ }^{29} \mathrm{Si}$ MAS NMR spectra for M-S-H synthesized in the presence of sodium hydroxide and sodium nitrate (1year) ( $\delta^{29} \mathrm{Si}$ in $\left.\mathrm{ppm} \pm 0.3 \mathrm{ppm}\right)$.

\begin{tabular}{|c|c|c|c|c|c|c|c|c|c|c|}
\hline & & & \multicolumn{7}{|c|}{$\delta^{29} \mathrm{Si}(\mathrm{M}-\mathrm{S}-\mathrm{H})$} & \multirow{3}{*}{$\begin{array}{l}\text { Am. silica } \\
\mathrm{Q}^{3}\left(\mathrm{SiO}_{2}\right) \\
-100.9\end{array}$} \\
\hline & & & $\mathrm{Q}^{1}$ & $\mathrm{Q}^{2} \mathrm{Na}$ & $\mathrm{Q}^{2}$ & $Q^{3} a$ & $Q^{3} b$ & $Q^{3} C$ & $Q^{2} / Q^{3}$ & \\
\hline & $\mathrm{Mg} / \mathrm{Si}$ & $\begin{array}{l}{[\mathrm{NaOH}]} \\
\mathrm{mmol} / \mathrm{l}\end{array}$ & -78.3 & -83 & -85.5 & -92.7 & -94.7 & -96.7 & & \\
\hline \multirow[t]{3}{*}{$20^{\circ} \mathrm{C}$} & 0.8 & 0 & 2 & 0 & 35 & 25 & 8 & 26 & 0.6 & 4 \\
\hline & & 10 & 4 & 9 & 28 & 37 & 13 & 9 & 0.6 & 0 \\
\hline & & 100 & 10 & 15 & 27 & 48 & 0 & 0 & 0.9 & 0 \\
\hline \multirow[t]{4}{*}{$50^{\circ} \mathrm{C}$} & 0.8 & 0 & 1 & 0 & 34 & 24 & 10 & 28 & 0.6 & 3 \\
\hline & & 50 & 2 & 7 & 28 & 30 & 5 & 27 & 0.6 & 1 \\
\hline & & 100 & 3 & 13 & 31 & 36 & 15 & 2 & 0.8 & 0 \\
\hline & & $\begin{array}{l}\text { [NaNO3] } \\
\mathrm{mmol} / \mathrm{l}\end{array}$ & & & & & & & & \\
\hline \multirow[t]{3}{*}{$50^{\circ} \mathrm{C}$} & 0.8 & 10 & 1 & 0 & 30 & 30 & 17 & 18 & 0.5 & 4 \\
\hline & & 100 & 2 & 0 & 29 & 34 & 19 & 12 & 0.4 & 4 \\
\hline & & 500 & 2 & 0 & 30 & 35 & 18 & 11 & 0.5 & 4 \\
\hline
\end{tabular}

Quantification error $\simeq \pm 10 \%$ of absolute amount of $(\% \mathrm{Si})+2.5 \%$.

Table 3: Summary of the presence of brucite and unreacted silica in the solid composition, the measured dissolved concentrations, $\mathrm{pH}$ values in the solutions in equilibrium with the M-S-H synthesized 2 years at $20^{\circ} \mathrm{C}$.

\begin{tabular}{|c|c|c|c|c|c|c|}
\hline $\begin{array}{l}\text { Initial } \\
\mathrm{NaOH}(\mathrm{mmol} / \mathrm{l})\end{array}$ & Brucite & $\begin{array}{l}\text { Amorphous } \\
\text { silica }\end{array}$ & $\begin{array}{l}\mathrm{Na} \\
\mathrm{mmol} / \mathrm{l}\end{array}$ & $\mathrm{Mg}$ & $\mathrm{Si}$ & $\mathrm{pH}\left(20^{\circ} \mathrm{C}\right)$ \\
\hline 3 & & traces & 0.38 & 0.39 & 1.44 & 8.3 \\
\hline 10 & & & 2.07 & 0.25 & 0.58 & 9.9 \\
\hline 25 & & & 8.06 & 7.64 & 5.17 & 10.2 \\
\hline 50 & & & 19.0 & 9.60 & 5.83 & 11.8 \\
\hline 100 & & & 61.8 & 9.89 & 10.6 & 12.5 \\
\hline 250 & traces & & 198 & 0.058 & 21.2 & 13.0 \\
\hline 500 & traces & & 450 & 0.001 & 34.9 & 13.3 \\
\hline
\end{tabular}

\section{List of Figures:}




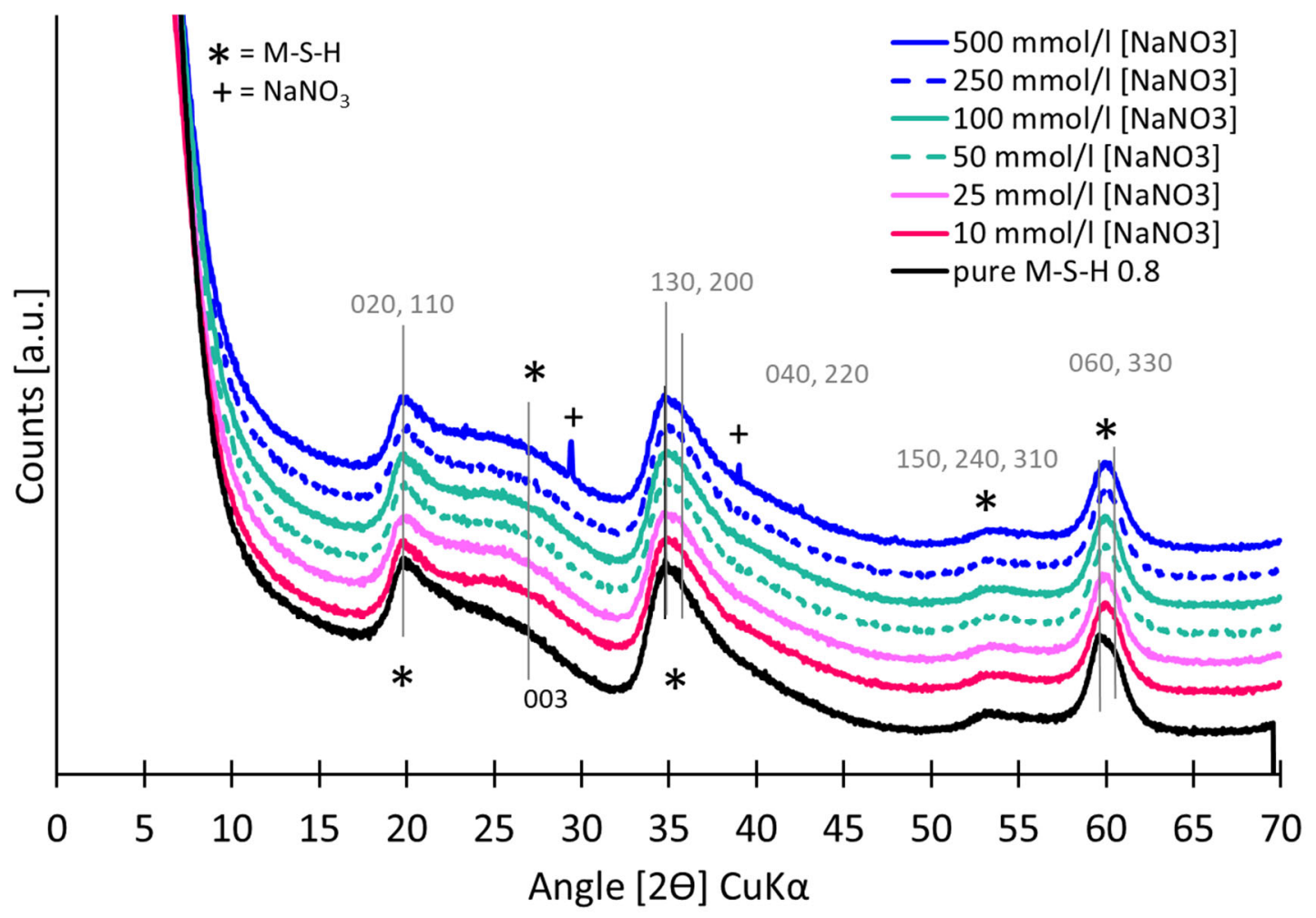

Figure 1: XRD patterns of M-S-H 0.8 samples synthesized in the presence of sodium nitrate compared to pure $\mathrm{M}-\mathrm{S}-\mathrm{H} 0.8$ after 1 year of curing at $50^{\circ} \mathrm{C}$. 


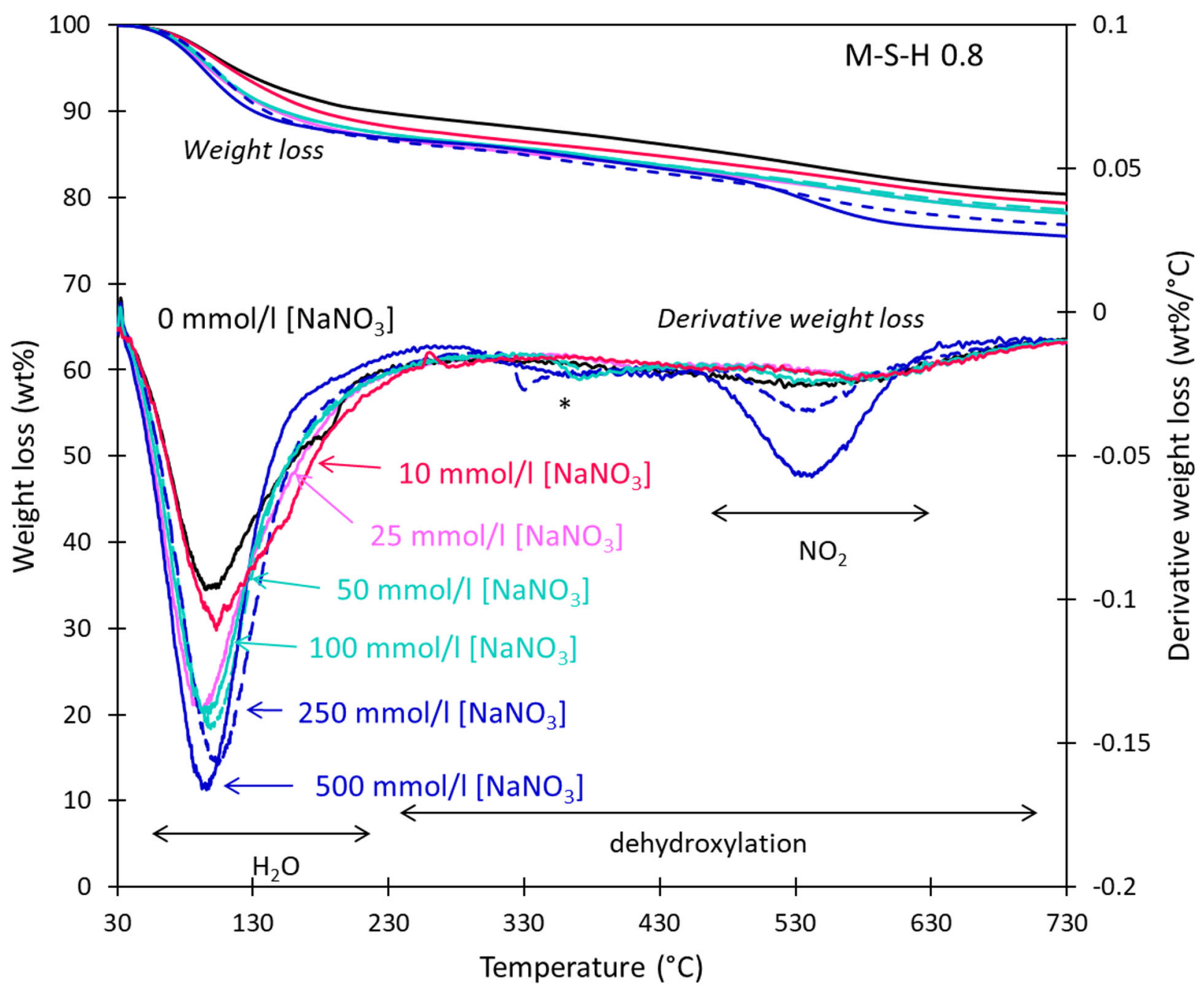

Figure 2: Thermogravimetric analysis of the M-S-H samples synthesized in the presence of sodium nitrate after 6 months of curing at $50^{\circ} \mathrm{C}$ compared to TGA of pure M-S-H $0.8\left({ }^{*}=\right.$ impurities). 


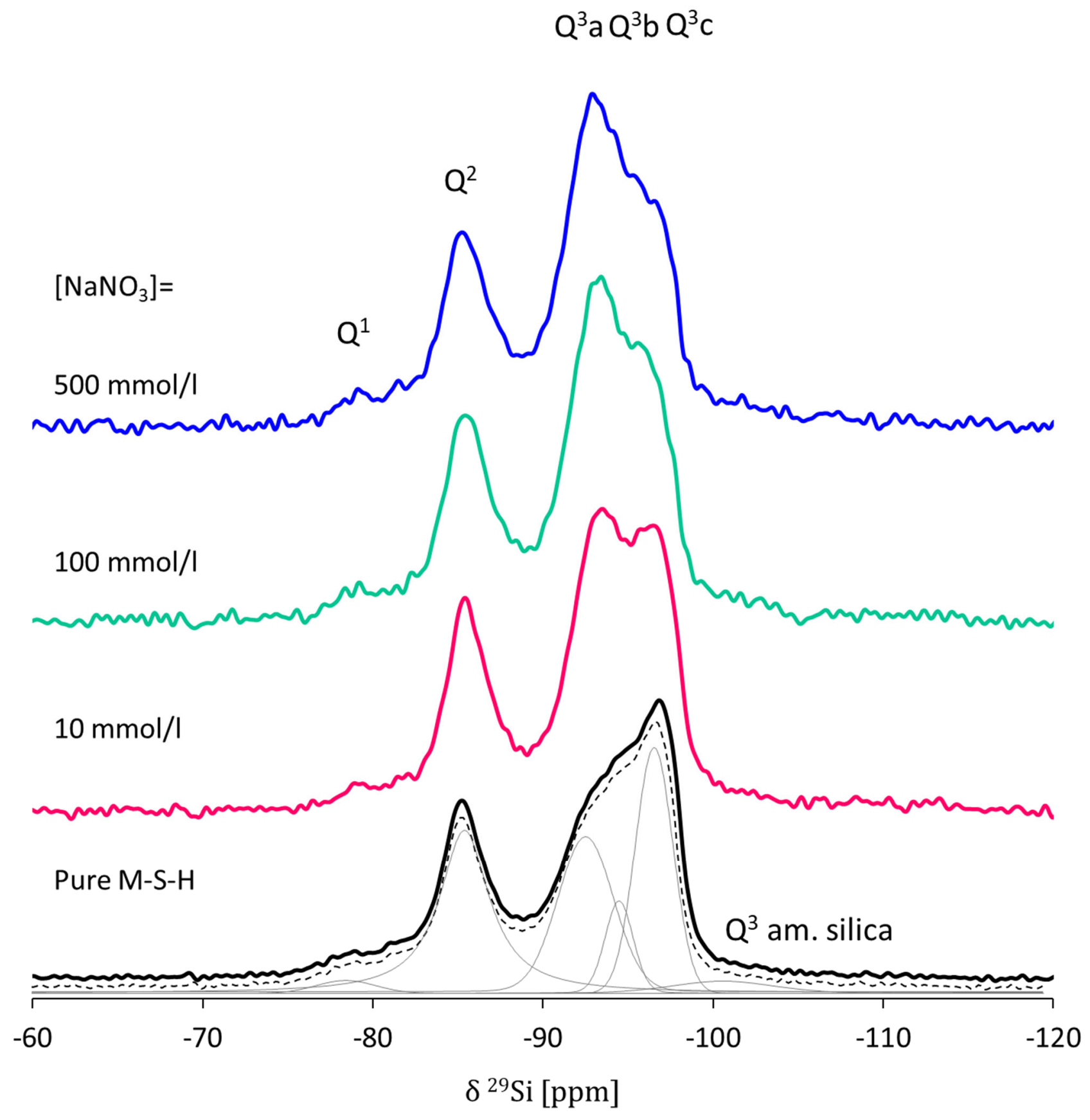

Figure 3: ${ }^{29} \mathrm{Si}$ MAS NMR spectra of M-S-H 0.8 samples synthesized in the presence of sodium nitrate after 1 year of curing at $50^{\circ} \mathrm{C}$. 


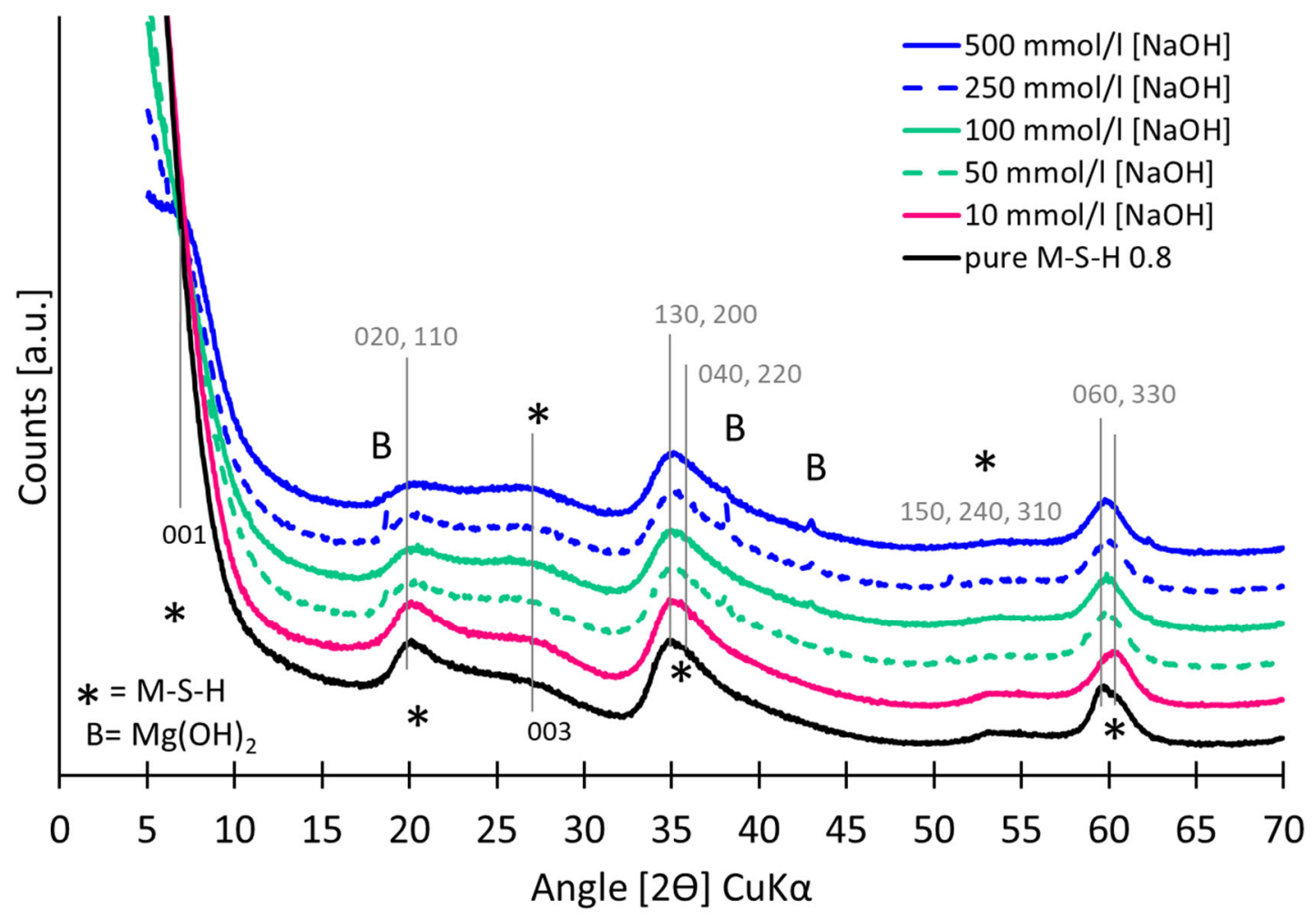

Figure 4: XRD patterns of M-S-H 0.8 samples synthesized in the presence of sodium hydroxide compared to pure M-S-H 0.8 after 2 years of curing at $20^{\circ} \mathrm{C}$. 


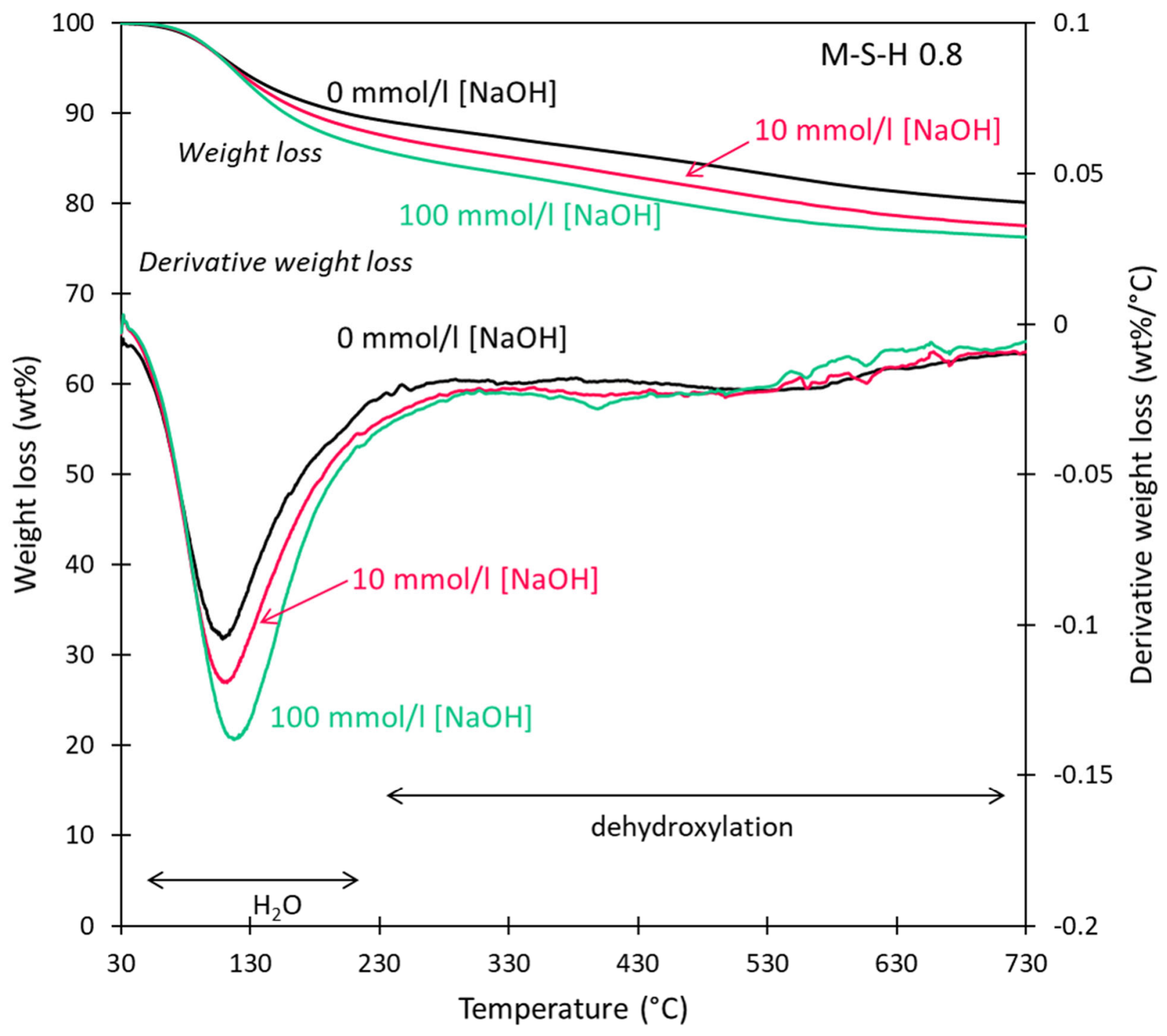

Figure 5: Thermogravimetric analysis of the M-S-H samples synthesized in the presence of sodium hydroxide after 1 year of curing at $20^{\circ} \mathrm{C}$ compared to TGA of pure M-S-H 0.8 . 


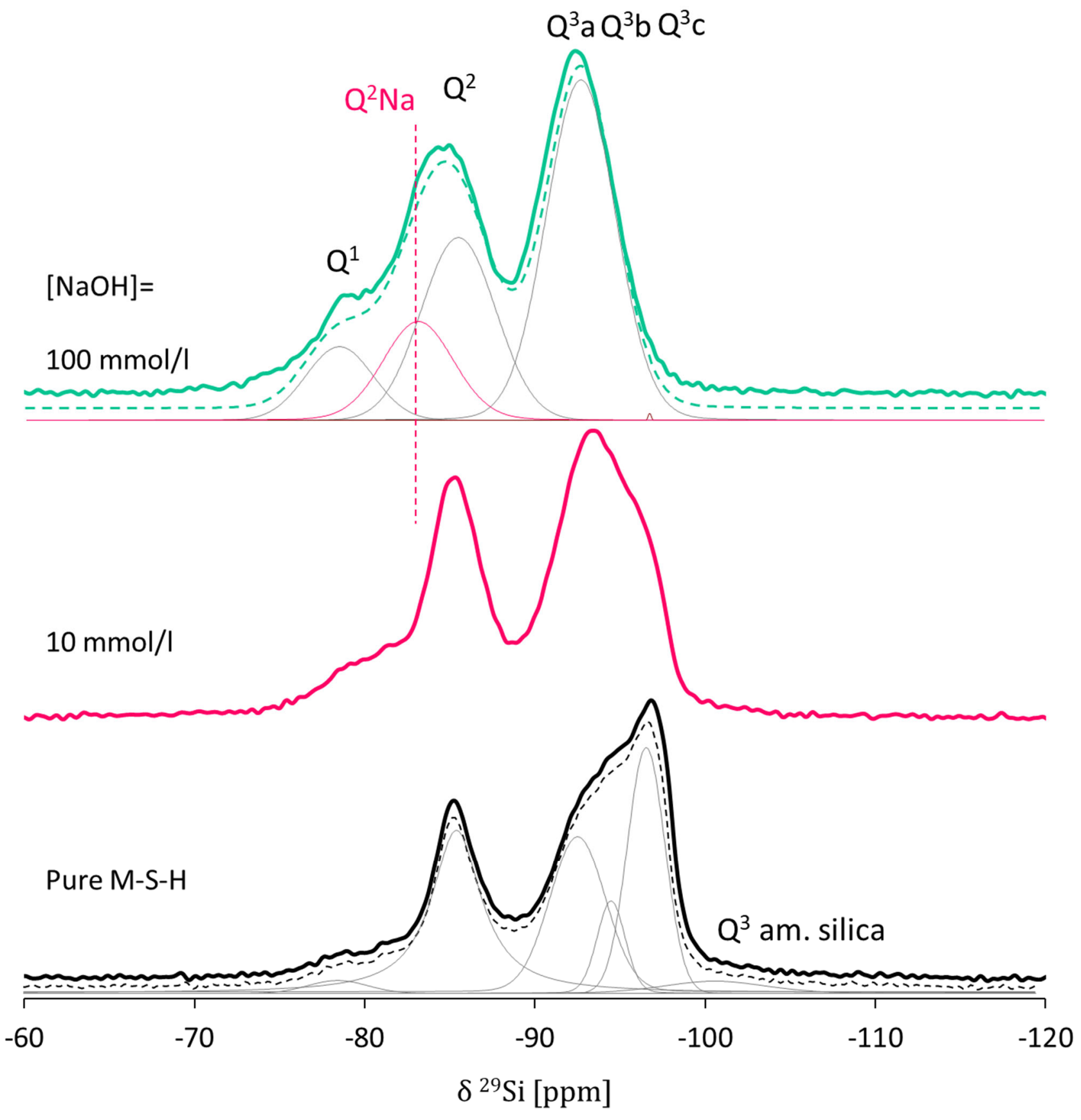

Figure 6: ${ }^{29} \mathrm{Si}$ MAS NMR spectra with assignments of single sites of M-S-H samples synthesized in the presence of sodium hydroxide after 1 year at $20^{\circ} \mathrm{C}$ compared to a pure $\mathrm{M}-\mathrm{S}-\mathrm{H}$, in dotted and grey lines are the details on the deconvolutions. 


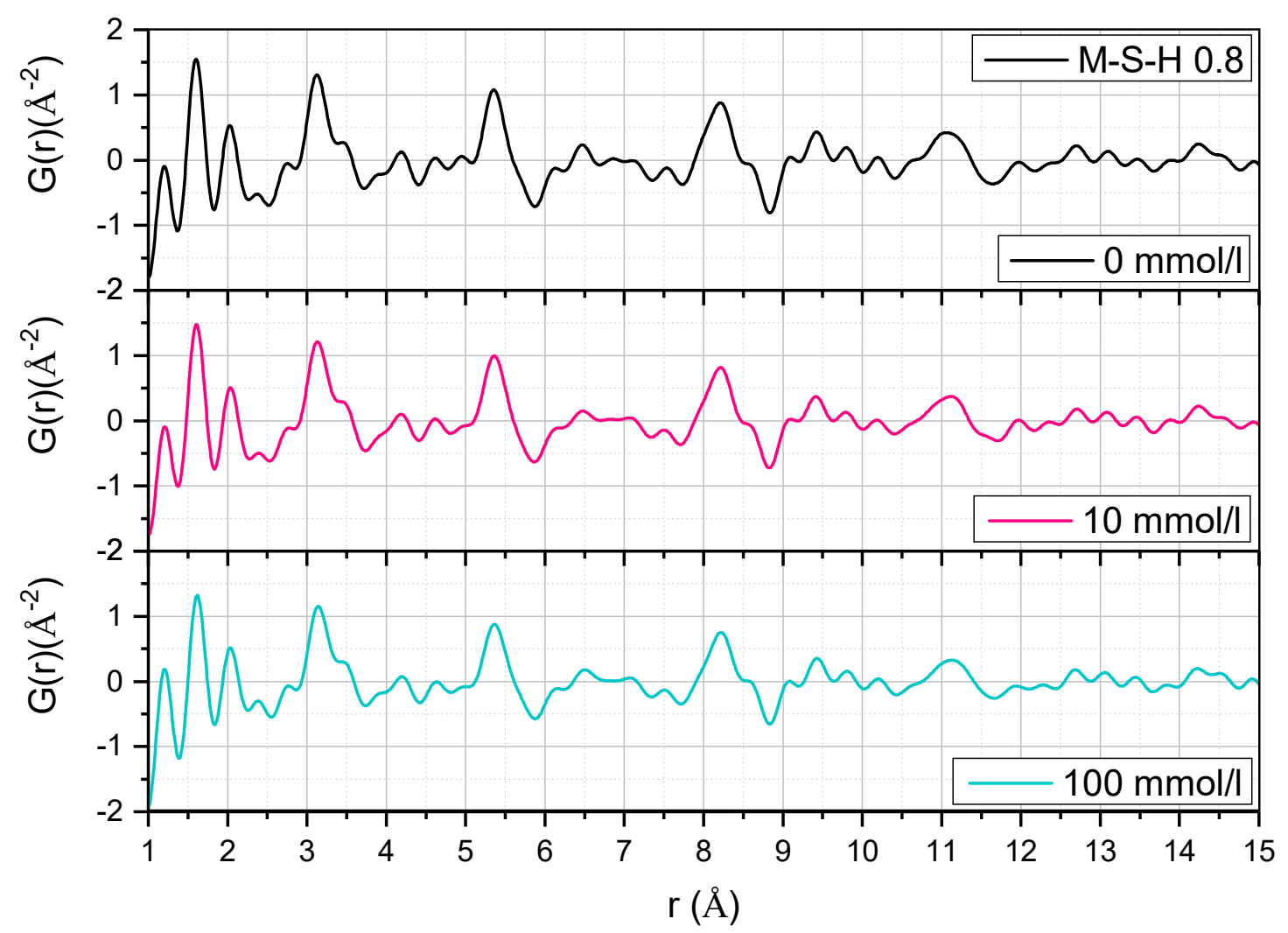

Figure 7: X-ray pair distribution function of M-S-H 0.8 synthesized in milliQ water, in 10 and $100 \mathrm{mmol} / \mathrm{l}$ of $\mathrm{NaOH}$ solution. 


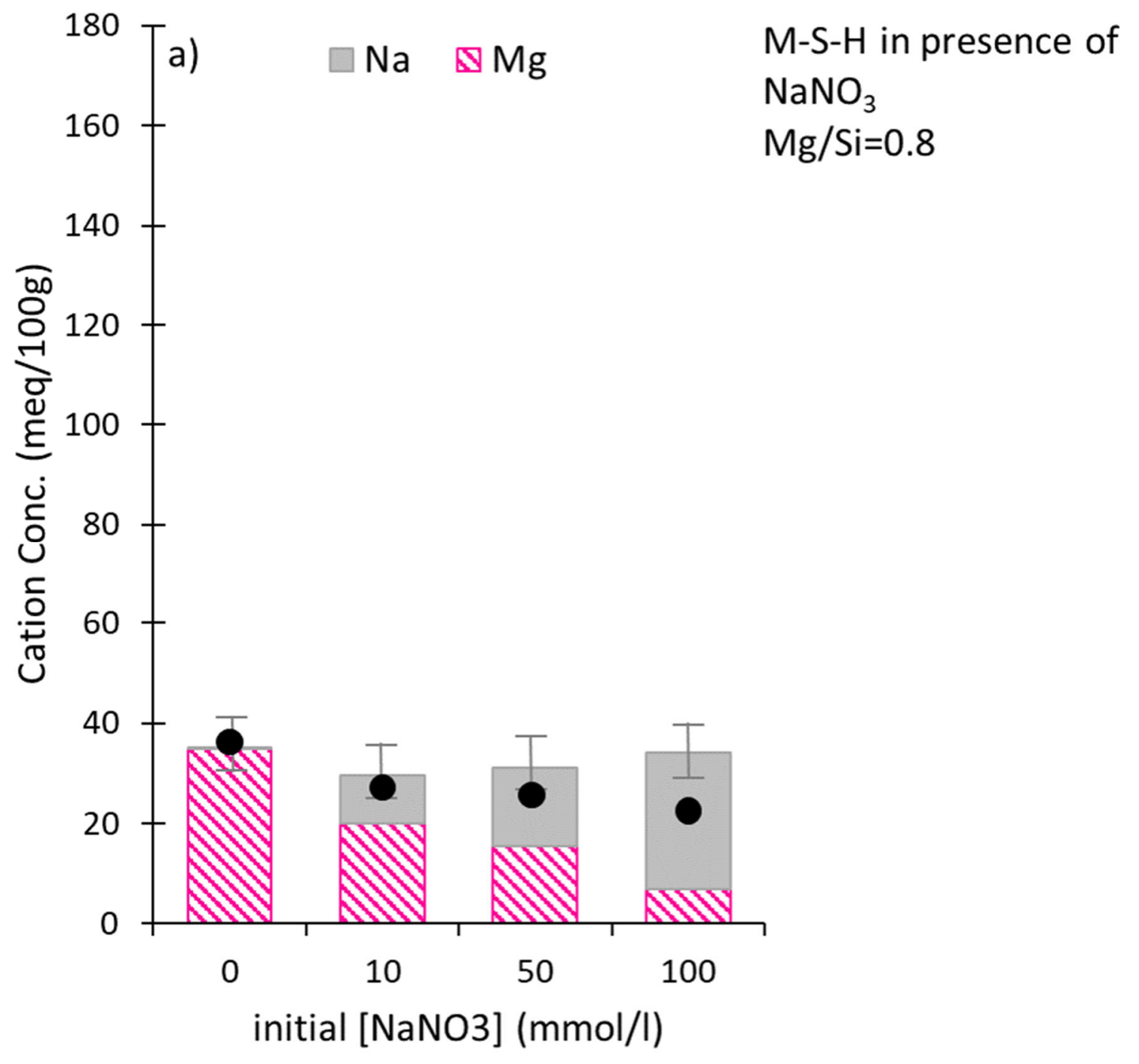




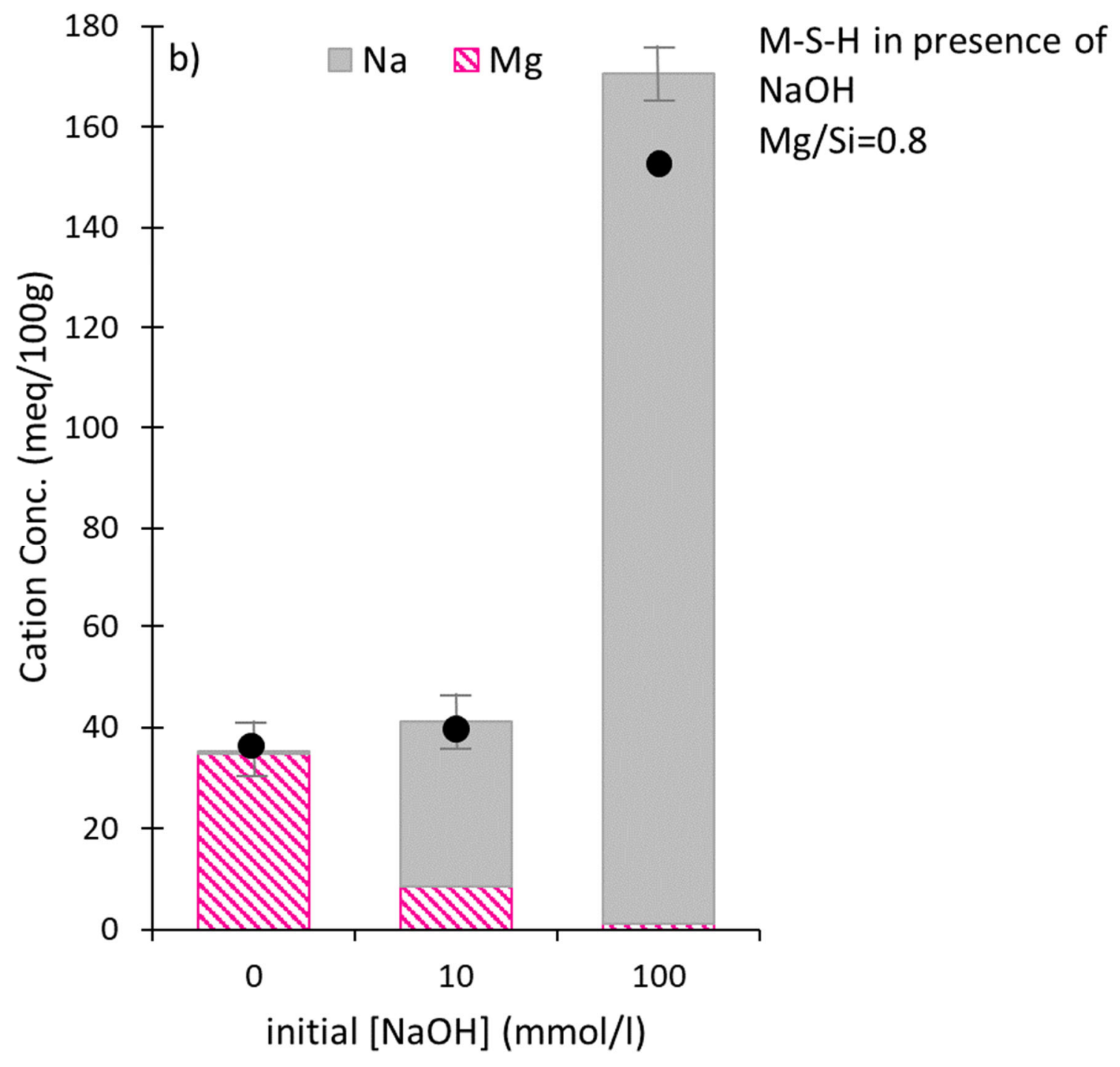

Figure 8: Concentrations of the cations sorbed on M-S-H samples synthesized in the presence of alkalis (1 or 2 years at $20^{\circ} \mathrm{C}$ ) measured by the cobalt hexamine method as a function of the initial concentration added. CEC measurements by colorimetry (black circles; the size of the symbols represent the error) have been added for comparison. 


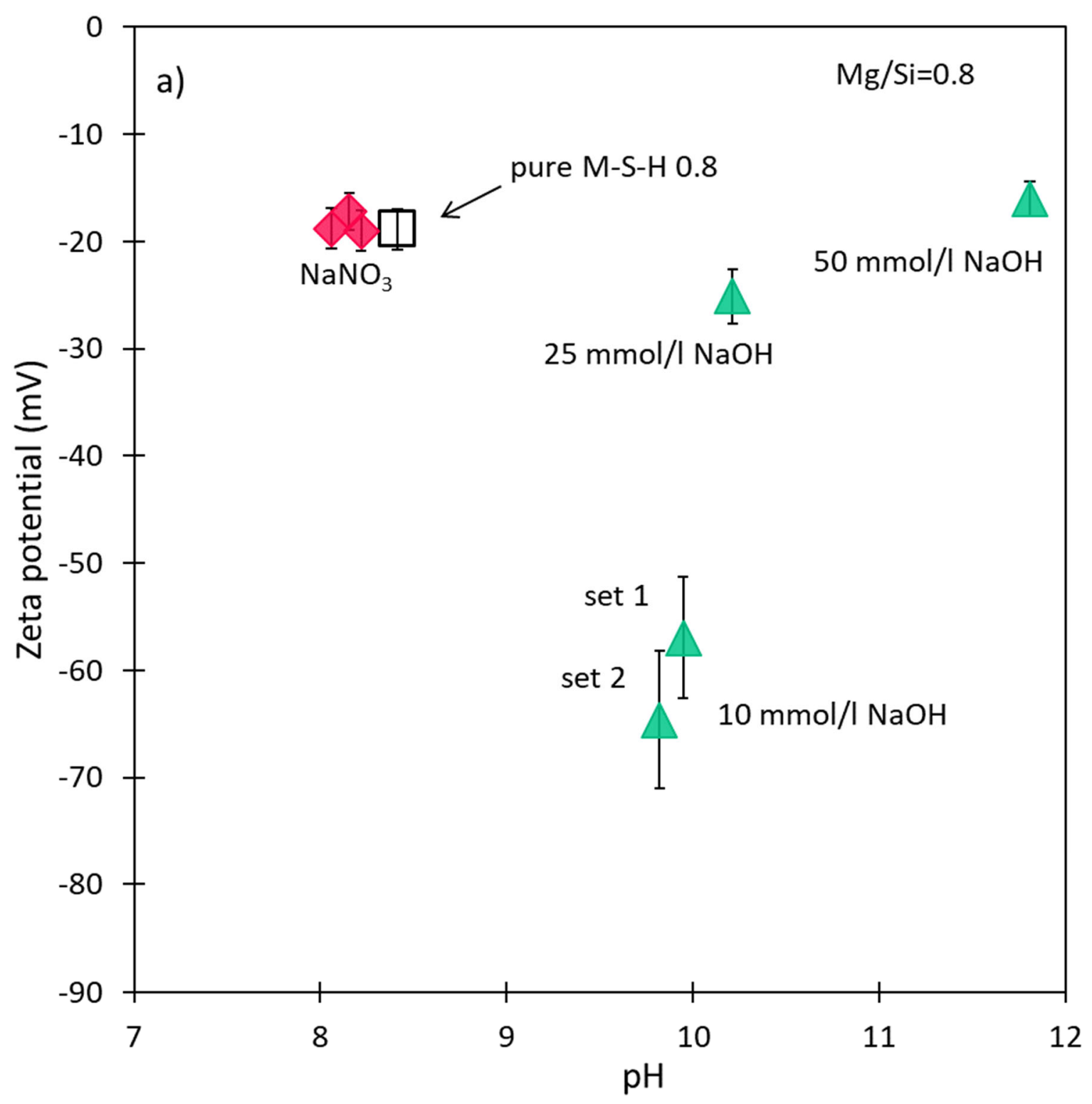




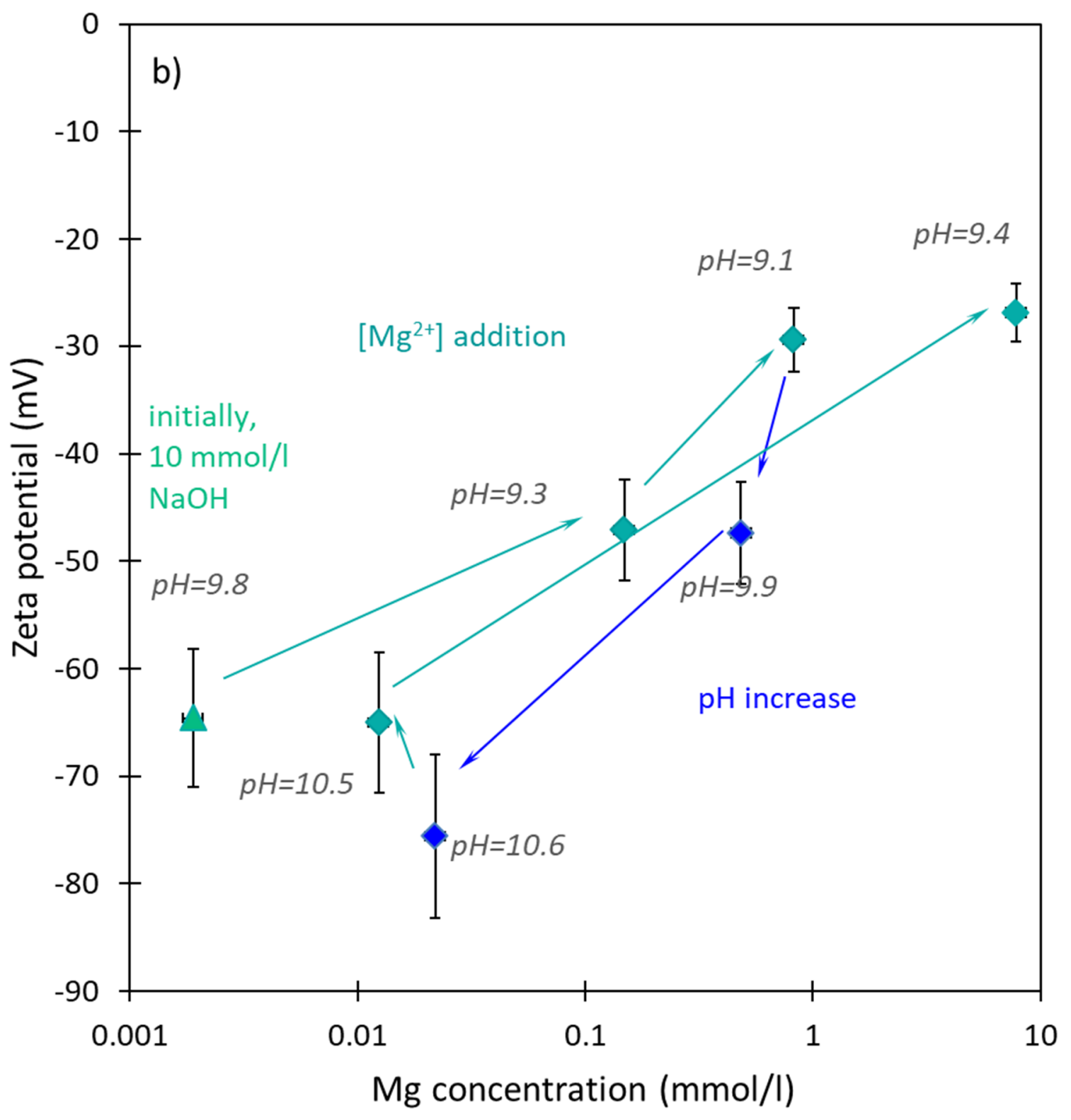

Figure 9: a) Zeta potential of M-S-H 0.8 samples synthesized in sodium nitrate and sodium hydroxide solutions versus the $\mathrm{pH}$ measured in the suspensions, b) titration of the second M-S-H 0.8 synthesized in sodium hydroxide $(10 \mathrm{mmol} / \mathrm{l} \mathrm{NaOH})$ by a magnesium solution $\left(\mathrm{MgCl}+\mathrm{Mg}(\mathrm{OH})_{2}, \mathrm{pH} 8.5-9\right)$ and sodium hydroxide solution. 


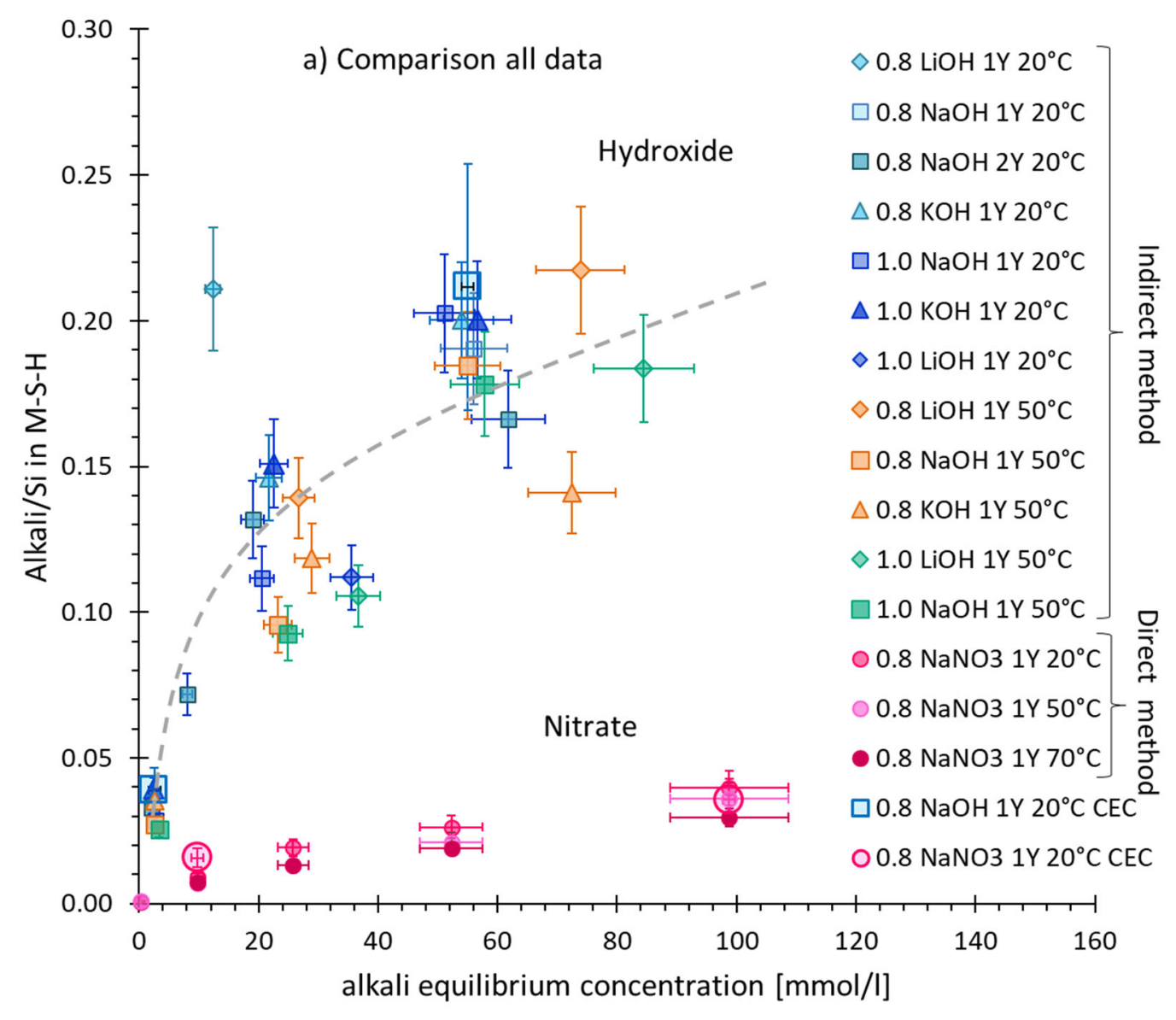




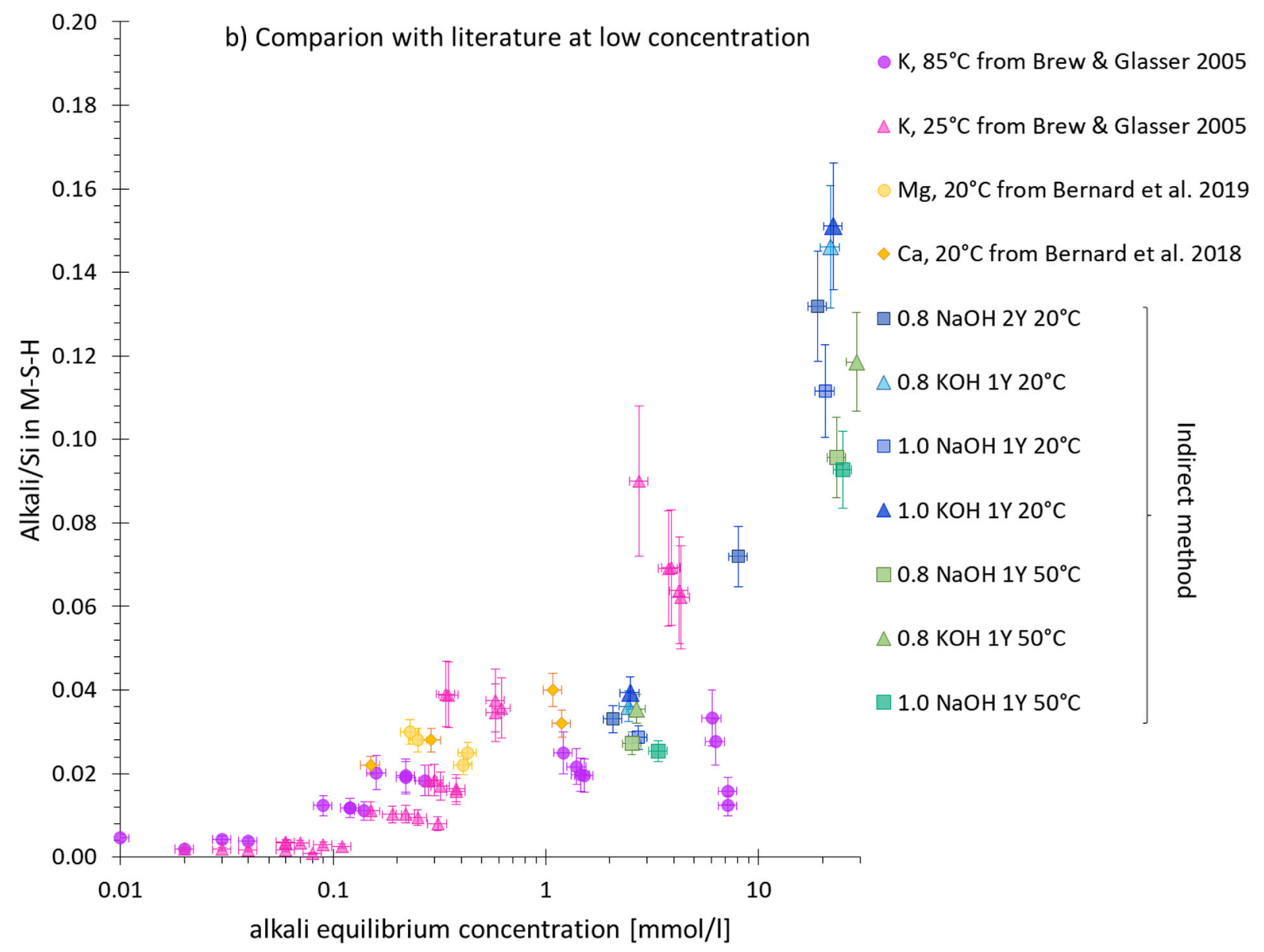

Figure 10: a) alkalis uptake in $\mathrm{M}-\mathrm{S}-\mathrm{H}(\mathrm{Mg} / \mathrm{Si}=0.8$ and $\mathrm{Mg} / \mathrm{Si}=1.0)$ as a function of the alkali concentration at equilibrium (measured), the results for $\mathrm{LiOH}, \mathrm{NaOH}, \mathrm{KOH}$ were calculated from mass balance (indirect method), the results for $\mathrm{NaNO}_{3}$ were calculated from dissolution (direct method); b) alkalis uptake in M-S-H as a function of the alkali concentration at equilibrium and comparison with the results from Brew et al. (21) and Bernard et al. $(25,40)$. 